\title{
OS100: A Benchmark Set of 100 Digitized UV-Visible Spectra and Derived Experimental Oscillator Strengths
}

\author{
Astrid S. Tarleton ${ }^{\mathrm{a}}$, Jorge C. Garcia-Alvarez ${ }^{\mathrm{a}}$, Anah Wynn, Cade M. Awbrey ${ }^{\mathrm{a}}$, Tomas P. Roberts ${ }^{\mathrm{a}}$, \\ Samer Gozem ${ }^{\mathrm{a}^{*}}$ \\ a Department of Chemistry, Georgia State University, Atlanta, GA 30302, United States. \\ *To whom correspondence should be addressed: sgozem@gsu.edu.
}

KEYWORDS: UV-visible spectroscopy, oscillator strength, transition dipole moment, extinction coefficient, attenuation coefficient. 


\begin{abstract}
Excited-state quantum chemical calculations typically report excitation energies and oscillator strengths, $f$, for each electronic transition. On the other hand, UV-visible spectrophotometric experiments report energy-dependent molar extinction/attenuation coefficients, $\varepsilon(v)$, that determine the absorption band line shapes. $\varepsilon(v)$ and $f$ are related, but this relation is complicated by various broadening and solvation effects. We fit and integrated experimental UV-visible spectra to obtain $f_{\text {exp }}$ values for absorption bands and estimated the uncertainty in the fitting. We derived $164 f_{\exp }$ values from 100 organic molecules ranging in size from 6-34 atoms. The corresponding computed oscillator strengths $\left(f_{\text {comp }}\right)$ were obtained with time-dependent density functional theory and a polarizable continuum solvent model. By expressing experimental and computed absorption strengths using a common quantity, we directly compared $f_{\text {comp }}$ and $f_{\text {exp }}$. While $f_{\text {comp }}$ and $f_{\exp }$ are well correlated (linear regression $\mathrm{R}^{2}=0.921$ ), $f_{\text {comp }}$ in most cases significantly overestimates $f_{\exp }$ (regression slope $=1.34$ ). The agreement between absolute $f_{\text {comp }}$ and $f_{\exp }$ values was substantially improved by accounting for a solvent refractive index factor, as suggested in some derivations in the literature. The 100 digitized UV-visible spectra are included as plain text files in the supporting information to aid in benchmarking computational or machine-learning approaches that aim to simulate realistic UV-visible absorption spectra.
\end{abstract}




\section{INTRODUCTION}

UV-visible spectrophotometry reports the range of frequencies of light absorbed by a sample and the strength of that absorbance. The former may be reported as energies, frequencies $(v)$, wavelengths $(\lambda)$, or wavenumbers $(\tilde{v})$. The latter, the absorption strength, is typically reported using the molar attenuation coefficient $(\varepsilon)$, an intensive property that appears in the Beer-Lambert law, ${ }^{1}$ or the closely related photoabsorption cross section.

Excited-state quantum chemical methods have reached an evident level of maturity in predicting excitation energies. The effort to improve these predictions continues, but hundreds of studies indicate that it is possible to predict energy of maximal absorption to a fraction of an $\mathrm{eV} .^{2}$ For instance, an extensive benchmark of time-dependent density functional theory (TD-DFT) vertical excitation energies indicates typical errors of $\sim 0.15-0.25 \mathrm{eV}$ for $\pi \rightarrow \pi^{*}$ transitions in organic dyes. ${ }^{3}$ These errors can be reduced to chemical accuracy $(<1 \mathrm{kcal} / \mathrm{mol}$ or $<0.043 \mathrm{eV})$ by going beyond the vertical approximation and using high-level excited-state ab initio methods. ${ }^{3-6}$

In comparison, there is a limited understanding of how well quantum chemical calculations can predict absorption strengths. This is not due to a lack of interest; predicting strengths is arguably as essential as predicting energies, with important applications in the design of dyes and in the identification and quantification of analytes, for instance. ${ }^{7-11}$ However, comparing computed and experimental absorption strengths is not straightforward. In computations, transition strengths for each electronic transition are often represented by a single value (typically, an oscillator strength or a transition dipole moment). On the other hand, due to broadening effects, molecules absorb light at a range of frequencies. Often, experiments report the point of highest absorbance for each absorption band $\left(\varepsilon_{\max }\right)$ and the corresponding frequency ( $v$ at $\varepsilon_{\max }$ ). However, the values of $\varepsilon_{\max }$ and $v$ at $\varepsilon_{\max }$ are affected by broadening and solvent effects that modulate the width, and therefore also the height, of the absorption bands (see Fig. 1). ${ }^{12,13}$ 


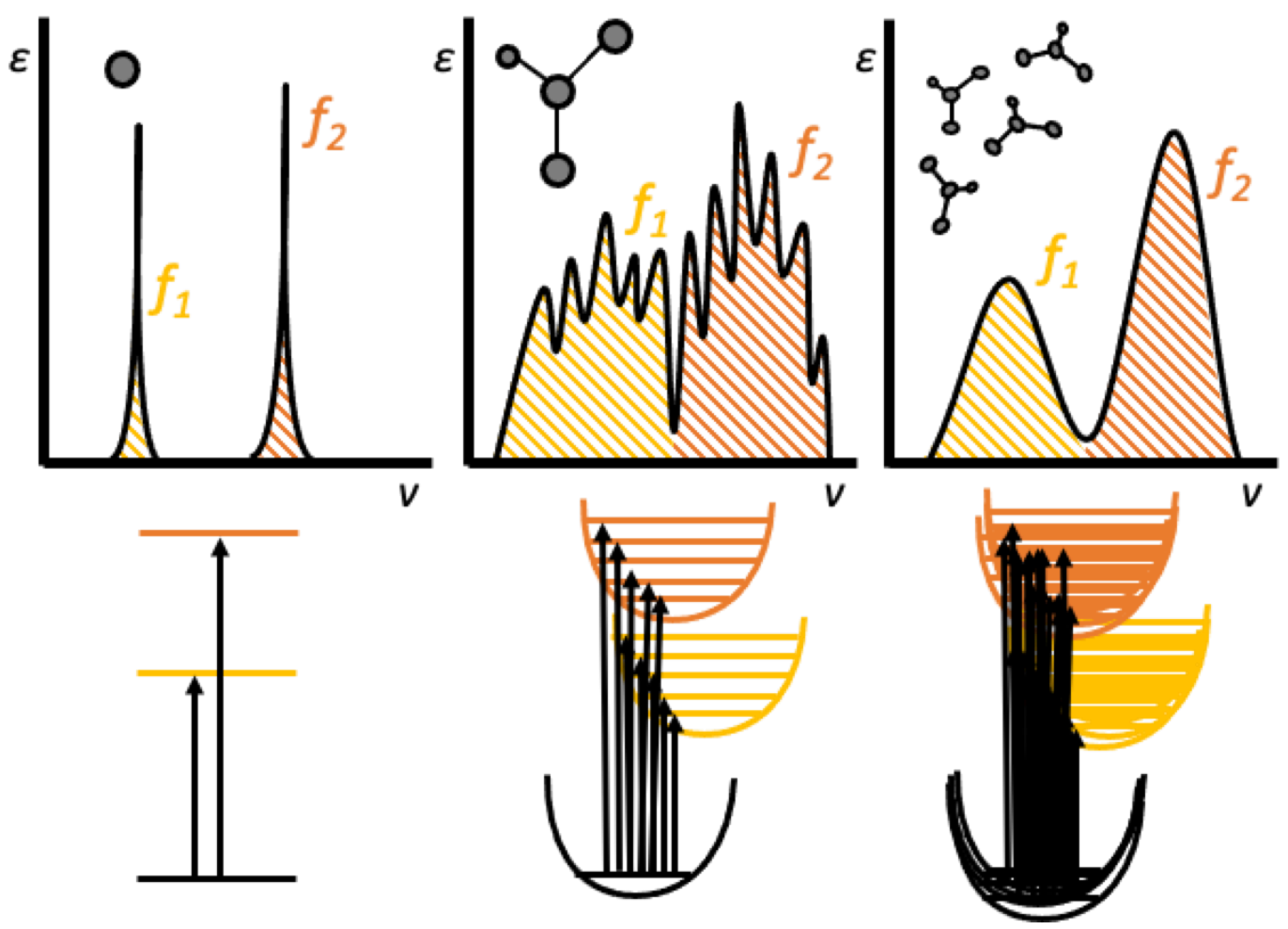

Figure 1. Line broadening in absorption spectra. Top panels show schematic UV-visible absorption spectra, while the bottom diagrams illustrate the corresponding transitions. In gas-phase atoms (left), where broadening is caused by lifetime, Doppler, and pressure effects, absorption lines typically appear sharp. Molecular spectra (center) are additionally broadened by vibrational and rotational energy levels, but the vibronic peaks may still be resolved, particularly in rigid gas-phase systems. In conformationally flexible or condensed-phase systems (right) each transition in the absorption spectrum appears as a broad band. In all cases, the total probability of the transition occurring is related to the area under the band for that transition (represented using $f_{1}$ and $f_{2}$ for each band).

The total probability for a molecule to get promoted to an electronically excited state is related to the integral of the attenuation coefficient over the full range of wavenumbers for that band. A single-valued experimental oscillator strength $\left(f_{\text {exp }}\right)$ for each band in the UV-visible spectrum can be obtained by integrating $\varepsilon(\tilde{v})$ over the range of wavenumbers, $\tilde{v}$, for the band, giving the area under that band (Fig. 1): ${ }^{14}$

$$
f_{\exp }=\frac{10^{3} \ln (10) \mathrm{m}_{e} c^{2}}{\mathrm{~N}_{\mathrm{A}} \pi \mathrm{e}^{2}} \int \varepsilon(\tilde{\mathrm{v}}) \mathrm{d} \tilde{\mathrm{v}}=\left(4.319 \times 10^{-9} \mathrm{M} \mathrm{cm}^{2}\right) \int \varepsilon(\tilde{\mathrm{v}}) \mathrm{d} \tilde{\mathrm{v}}
$$

In equation (2), $m_{e}$ is the mass of the electron, $c$ the speed of light in vacuum, $N_{A}$ is Avogadro's constant, and $e$ is the elementary charge. The numerical value in the second equality can be used when $\varepsilon(\widetilde{v})$ and $\tilde{v}$ are in units of $\mathrm{M}^{-1} \mathrm{~cm}^{-1}$ and $\mathrm{cm}^{-1}$, respectively. The limits of integration should go over the range of wavenumbers for the band of interest. This is trivial for well-defined and separated bands like those shown in Fig. 1, but for overlapping bands where multiple transitions 
contribute to absorbance at a common wavenumber, it becomes necessary to find a way to perform the integration in equation (2) for a specified band. This is discussed further in the Methodology section.

The oscillator strength can also be derived from quantum mechanically computed transition dipole moments: ${ }^{15}$

$$
f_{\text {comp }}=\frac{4 \pi m_{e} v}{3 \hbar}\left|\left\langle\psi_{I}|\boldsymbol{r}| \psi_{F}\right\rangle\right|^{2}
$$

In equation (3), $v$ is the frequency for the transition, $\hbar$ is the reduced Planck constant, and $\left\langle\psi_{\mathrm{I}}|\mathbf{r}| \psi_{\mathrm{F}}\right\rangle$ is the transition dipole moment connecting the initial $\left(\psi_{\mathrm{I}}\right)$ and final $\left(\psi_{\mathrm{F}}\right)$ electronic state wave functions. When multiple transitions contribute to a band in a UV-visible spectrum, it is possible to sum equation (3) for several final state transitions.

Equations (2) and (3) give experimental and computed oscillator strengths, respectively, in a common quantity that is directly comparable. However, very few experimental studies report $f_{\exp s \text {, }}$ while even fewer report the protocol used to derive $f_{\text {exp }}$ from the UV-visible absorption spectrum. Therefore, most existing benchmark studies employ high-level ab initio methods as the reference, rather than using an experimental reference. ${ }^{2}$ There is still limited understanding of how computed oscillator strength calculations compare to experimental ones.

Compounding the difficulty in comparing computations and experiments is that equations (2) and (3) were derived for systems in vacuo and are not exact for molecules in solution. Specifically, accounting for the refractive index of the solvent $(n)$ is necessary in one or in both equations. How to do that is a topic of debate starting from the $1930 \mathrm{~s}^{16}$ that remains unresolved. For instance, reports in the literature often use equation (2) as-is, ${ }^{17-20}$ while others have multiplied equation (2) by factors of $n^{-2},{ }^{21,22} n^{-1},{ }^{23,24} n,{ }^{25-27}$ or some more complicated function of $n .^{28-32}$ In this manuscript, we start with the assumption that calculations using a polarizable continuum model (PCM) to account for the effect of solvation on vertical excitation already account for the effect of refractive index on oscillator strength (see Methodology). We also initially use equation (2) as-is to derive the experimental oscillator strengths. We then discuss the effect of the refractive index after presenting the results.

In a 2013 review on TD-DFT benchmarks, Laurent and Jacquemin cited several studies that included oscillator strength benchmarks up to that time. ${ }^{2}$ Most of these studies focused on a few molecules, and compared computed oscillator strengths with other theoretical results, or a mix of theory and experiments. A number of studies since then have focused on comparing TD-DFT 
calculations with high-level ab-initio calculations for small molecules. ${ }^{33,} 34$ The most extensive validation against experiments, to our knowledge, was published by Jacquemin et al. ${ }^{35}$ for a series of thirty related anthraquinones. ${ }^{36}$

We collected and digitized one-hundred solution-phase UV/visible spectra of organic molecules ranging in size from 6-34 atoms. The systems range in type from simple unsaturated hydrocarbons to larger heteroatomic chromophores like substituted azobenzenes. This includes a few sulfur, phosphorous, and halogen-containing molecules (no heavier than bromine). Out of the 100 molecules, 19 are molecular anions and 12 are molecular cations. We refer to the benchmark set as OS100. We note that there is no relation to the GW100 benchmark of ionization potentials and electron affinities, ${ }^{37}$ only that both sets of benchmarks include 100 molecules. The $100 \mathrm{UV}$ visible spectra were all obtained from a common source, the UV Atlas of organic compounds. ${ }^{38}$ The UV Atlas is one of the resources used by the NIST online database, and reports experimental details including the solvent, concentration at which the spectra were taken, and spectral resolution for the all the measurements. $164 f_{\exp }$ values were derived from well-defined bands appearing in these spectra. The following sections introduce the benchmark set and describe the fitting and scoring system. TD-DFT calculations are presented with a popular functional, B3LYP, to provide a preliminary comparison of $f_{\exp }$ and $f_{\text {comp }}$. More extensive benchmarking with other functionals and wave function methods is left to future work. The TD-B3LYP $f_{\text {comp }}$ values are well-correlated with $f_{\exp }$ (linear regression $\mathrm{R}^{2}=0.921$ ), but they systematically overestimate the oscillator strength (regression slope $=1.34$ ). This large slope could potentially be explained by a refractive index factor missing in equations (2) and/or (3). 


\section{METHODOLOGY}
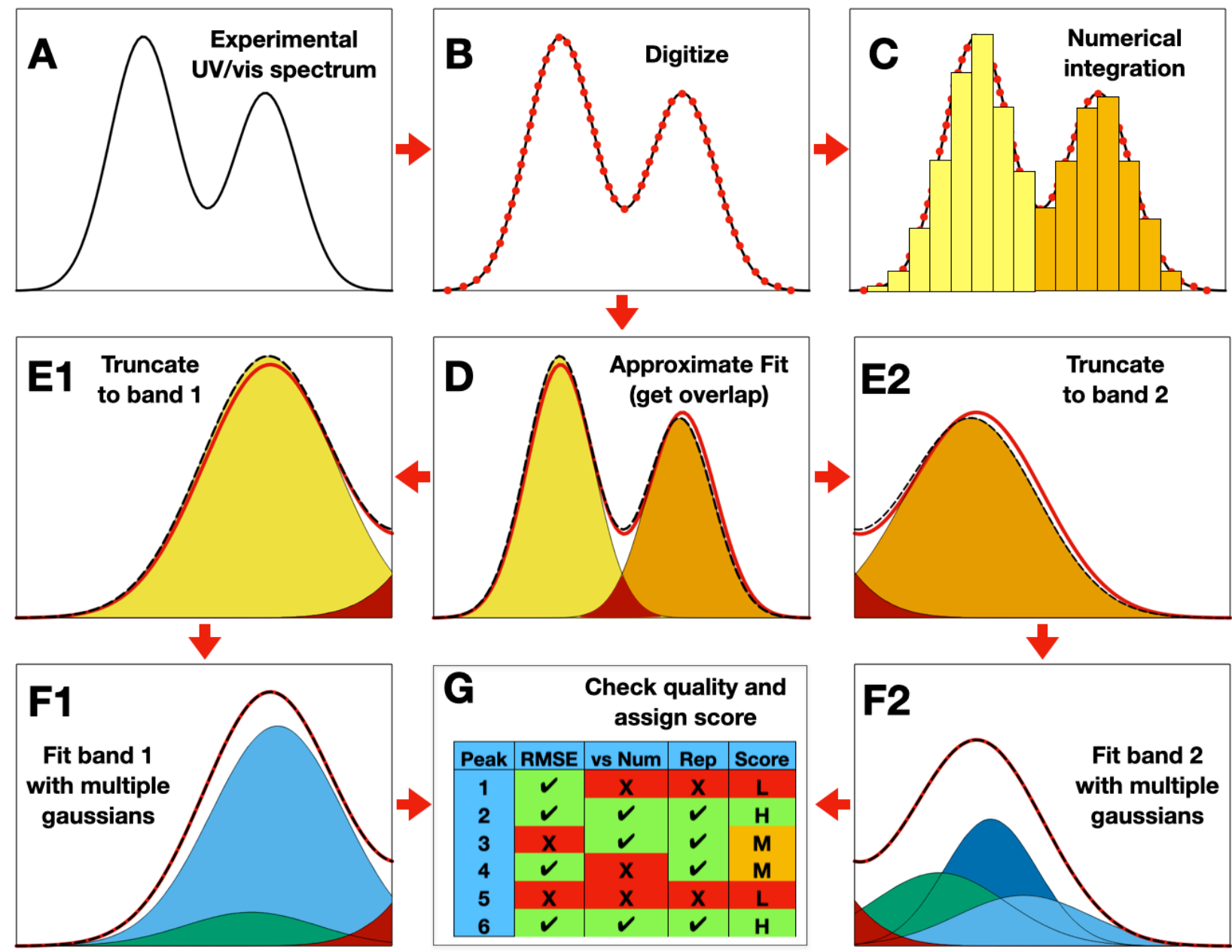

Figure 2. A schematic figure of the protocol used to derive oscillator strengths from experimental UV/vis spectra. See text for details.

The protocol to obtain $f_{\text {exp }}$ from UV-visible spectra is schematically shown in Fig. 2. The UVvisible spectra were digitized (panel B) and numerically integrated using the midpoint method (panel C) to find the areas under each band. The limits of the numerical integration were set as the minima in $\varepsilon$ at the low and high energy range of each band when a band can be distinctly identified. Bands with an oscillator strength below 0.01 were not considered. From here on, we refer to values of $f_{\text {exp }}$ obtained by numerical integration as $f_{\text {exp }, n}$. In cases of incomplete or overlapping bands (like the example in Fig. 2), numerical integration does not correctly treat the overlap region; it accounts for spillover from nearby bands and/or misses part of the band that is outside of the numerical integration window. This error is in addition to numerical errors associated with finite-width 
midpoint rule integration. However, in case of well-separated bands (like those in Fig. 1 right), $f_{\text {exp }, n}$ is expected to be a good approximation for $f_{\text {exp }}$.

In addition to numerical integration, the UV-visible spectra were analytically integrated after curve fitting. Since multiple factors contribute to broadening of UV-visible spectra, neither a single Voigt function nor a single Gaussian function could accurately fit the absorption bands. Therefore, initially, the spectra were fit using a minimal number of Gaussian curves to describe overlap regions between bands (see panels $\mathbf{D}, \mathbf{E 1}$, and E2). Then, for each band, the area under the curve was fit using an increasing number of Gaussian curves while freezing the fits for the nearby overlapping bands, until convergence (panels F1 and F2). Convergence was monitored using the normalized root-mean-square deviation (\%nRMSD, defined in Sources of Error). In most cases, $\%$ nRMSD was kept below $0.5 \%$. In difficult to converge cases, a system was considered converged when \%nRMSD does not change upon adding Gaussian curves. Bands that did not converge were discarded from the benchmark set (i.e., are not included among the 164 transitions). The area under the curve was obtained by analytical integration of the Gaussian functions included in fitting that band, excluding the spillover from nearby bands. Oscillator strengths derived in this way are labelled $f_{\text {exp,g. }}$.

In cases of strongly overlapping bands where the bands could not be reliably deconvoluted, the bands were included in a single integration and assigned one oscillator strength value, which can be compared to the sum of the computed oscillator strengths for the bands.

Steps B-F were repeated a second time for each molecule, by a different person, using a different resolution for the digitization. This ensured reproducibility and provided an estimate of errors introduced during each of the digitization, numerical integration, and fitting processes.

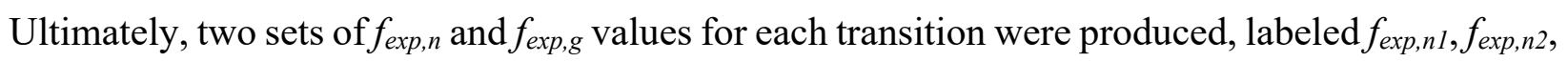
$f_{\text {exp,gl }}$, and $f_{\text {exp,g2 }}$. The higher resolution data are labeled $f_{\text {exp }, n 1}$ and $f_{\text {exp,gl }}$ while the lower resolution data are labeled $f_{\text {exp,n } 2}$ and $f_{\text {exp,g2 }}$. The $f_{\text {exp,n }}$ and $f_{\text {exp,g }}$ data reported in this work are the averages of the two trials. The quality of the integration was then scored (see Sources of Error section), and each band was assigned a score indicating confidence in the integration process (panel $\mathbf{G})$. This process was repeated for the 100 molecules.

Quantum chemical geometry optimizations were carried out at the density functional theory (DFT) level of theory using the B3LYP functional ${ }^{39,40}$ and $6-31+\mathrm{G}^{*}$ basis set for all molecules. Frequency calculations were carried out at the same level of theory to ensure that exclusively 
positive frequencies are obtained for all molecules. TD-DFT calculations were carried out using the same functional and basis set. The the integral equation formalism of PCM (IEF-PCM) was used to account for the solvent effect. ${ }^{41}$ The dielectric constant and optical dielectric for each solvent are obtained from the Minnesota solvent descriptor database based on the solvent used in the corresponding experiment. ${ }^{42}$ The list of solvent and solvent descriptors used are listed in Table $\mathrm{S} 1$ in the Supporting Information document. The IEF-PCM solvation was performed using a nonequilibrium linear response formalism to account for the effect of solvation on the excitations. ${ }^{43}$

The geometry optimizations and TD-DFT calculations were performed by two different individuals, to check for consistency. Differences between the two trials could be easily reconciled and one final set of computational data was produced, labeled $f_{\text {comp }}$.

The TD-DFT calculations included 30 singlet states. For all molecules, the $30^{\text {th }}$ excited state was higher in energy than the upper limit of the experimental spectrum $\left(v_{\max }\right)$. To compare computed $\left(f_{\text {comp }}\right)$ and derived from experiment $\left(f_{\text {exp }}\right)$ oscillator strengths, it is necessary to assign computed transitions to UV-visible absorption bands. In many cases, the computed transition energies fall within the range of the experimental band energies, between $v_{\min }$ and $v_{\max }$, where the $v_{\min }$ and $v_{\max }$ limits are the same limits used for the numerical integration (see Fig. $\mathbf{2}$ panel $\mathbf{C}$ for a schematic representation). Specifically, $v_{\min }$ and $v_{\max }$ are defined as the lower and upper wavenumber limits where the molar extinction coefficient is at a minimum. In some cases, multiple computed transitions fall within a band. In these cases, $f_{\text {comp }}$ is the sum of the oscillator strengths of those transitions. Plots of the digitized UV-visible spectra, their Gaussian fitting functions, and computed TD-B3LYP/6-31+G* IEF-PCM transition stick spectra are included as a supporting document (SIplots).

In some cases, there is a high confidence in the assignment of computed transitions to bands, since there is only one transition per band in the near-UV and visible range. However, there are also cases where the assignment is not straightforward, particularly if multiple transitions appear close to an overlap region between two bands. Therefore, while categorizing transitions based on whether their energies fall within the experimental $v_{\min }$ and $v_{\max }$ is a practical approach, it is not foolproof. For instance, by reviewing the SIplots, five exceptions were recognized where the computed transitions fall outside of the experimental band but can be assigned with a high degree of confidence to that band, or where a transition falls within one band but can be assigned to another. Those five exceptions are labeled in SIplots and have been used to update the 
corresponding $f_{\text {comp }}$ values. For more extensive benchmarking, however, a more reliable and fully automated approach is necessary for assigning the computed transitions.

WebPlotDigitizer was used to digitize the UV-visible spectra ${ }^{44}$ and Excel's Solver plugin was used to fit the spectra using the nonlinear generalized reduced gradient algorithm. ${ }^{45}$ Regression and confidence interval analyses were carried out in Mathematica. ${ }^{46}$ The two sets of computations were carried out using the random phase approximation formulation of TD-DFT ${ }^{47}$ in Q-Chem ${ }^{48}$ and using the default TD-DFT formulation in Gaussian 16, ${ }^{49}$ respectively. The latter are the ones reported for $f_{\text {comp }}$.

\section{SOURCES OF ERROR}

When using experimental data as a benchmark, it is important to recognize sources of experimental errors. These include errors introduced by instrumentation, experimental design, sample quality (impurities, uncertainties in concentration, concentration-dependent aggregation effects, etc.), and human error. Some of these issues have been discussed at length in the literature, but it remains difficult to quantify the magnitude of the errors. ${ }^{50-52}$ One concern raised for experimental oscillator strengths derived from photoabsorption spectroscopy and the BeerLambert law is that errors introduced by line-saturation effects could result in the underestimation of the experimentally measured $f_{\text {exp }}$ relative to the "true" strength $f .{ }^{34,53}$ This problem is clearly described by Chan et al. ${ }^{52}$ However, it appears that such issues are particularly problematic for narrow bands (e.g., well-resolved gas-phase spectra where there are vibronic peaks with full-width at half-maxima that are on the order of hundreds of $\mathrm{cm}^{-1}$ ). The severity of these errors is reduced for broad absorption bands that are thousands of $\mathrm{cm}^{-1}$ across, like most of the bands used in this work.

We do not attempt to quantify the errors in $f_{\text {exp }}$, although we recognize that they exist. However, the uncertainty in $f_{\exp }$ is yet another motivation for an extensive benchmark study comparing experimental and computed oscillator strengths. By determining random or systematic errors against computations, particularly for high-level quantum chemical calculations, errors in the experimental measurements could be better understood. ${ }^{54}$

Errors in $f_{\text {comp }}$ exist when the transition dipole moment in equation (3) is computed using approximate rather than exact wave functions. This error can be quantified by systematically moving towards high-level quantum chemical methods, ${ }^{2,33-35}$ but this limits benchmarking to small 
molecules where these methods are affordable. Calculations of $f_{\text {comp }}$ in this work also neglect nuclear motion, which can often be justified for rigid molecules within the Born-Oppenheimer and Condon approximations ${ }^{55}$ but does not consider variations of oscillator strength with changes in the conformation of flexible molecules. Finally, approximate PCM solvation models may not correctly capture the effect of solvation on $f_{\text {comp }}$. The magnitudes of all these errors are difficult to quantify as well, which is why extensive benchmarking against experimental oscillator strengths is needed.

Here, we focus on uncertainties introduced in the fitting procedure itself, which we identify using four metrics:

- $\quad$ ogn: The percentage difference between $f_{\text {exp,g }}$ and $f_{\text {exp }, n}$. In practice, we compute two sets of $\%$ gn values then take the average:

$$
\% g n=\frac{1}{2}\left(\frac{\left|f_{\text {exp }, g 1}-f_{\text {exp }, n 1}\right|}{f_{\text {exp }, g 1}}+\frac{\left|f_{\text {exp }, g 2}-f_{\text {exp }, n 2}\right|}{f_{\text {exp }, g 2}}\right)
$$

Values of $\%$ gn ranged from $0.0 \%$ to $32.7 \%$, with an average of $6.0 \%$, a first quartile of $1.5 \%$, median of $4.5 \%$, and third quartile of $7.5 \%$.

- \%gg: The percentage difference between $f_{\text {exp,gl }}$ and $f_{\text {exp,g2 }}$. This as an indicator of the reproducibility of the Gaussian fitting procedure performed by two different persons:

$$
\% g g=\frac{2\left|f_{\text {exp, }, 1_{1}}-f_{\text {exp }, g 2}\right|}{\left(f_{\text {exp }, g 1}+f_{\text {exp }, g_{2}}\right)}
$$

Values of $\% \mathrm{gg}$ ranged from $0.0 \%$ to $37.9 \%$, with an average of $4.2 \%$, a first quartile of $0.9 \%$, median of $2.6 \%$, and third quartile of $5.1 \%$.

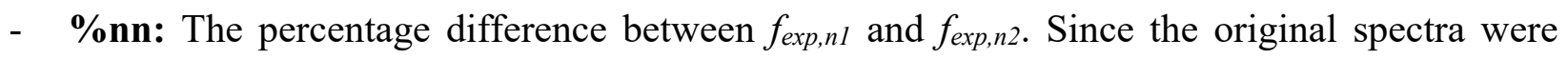
plotted on a logarithmic scale, this exacerbates errors in the digitization of the UV-visible spectra, particularly for intense bands. Therefore, \%nn reflects the uncertainty introduced by both the digitization and numerical integration procedures. \%nn is computed in the same way as \%gg in equation (5) but using the numerical $f_{\text {exp,n1 }}$ and $f_{\text {exp }, n 2}$. Values of \%nn ranged from $0.0 \%$ to $7.0 \%$, with an average of $1.4 \%$, a first quartile of $0.5 \%$, median of $1.1 \%$, and third quartile of $1.8 \%$.

- \%nRMSD: The normalized root-mean-square deviation between the digitized UV-visible spectrum and the Gaussian deconvoluted spectrum. The \%nRMSD is computed using: 


$$
\% n R M S D=\frac{\sqrt{\sum_{i=1}^{n} \frac{\left(\varepsilon_{\left.i, f i t^{-} \epsilon_{i}\right)^{2}}\right.}{n}}}{\epsilon_{\max }-\epsilon_{\min }}
$$

In equation (6), for each point $i$ in the digitized spectrum, $\varepsilon_{i}$ is the experimental attenuation coefficient at that point, $\varepsilon_{i, f i t}$ is the corresponding value at that point obtained from the sum of the Gaussian curves used in the fitting of the band, and $n$ is the total number of points used in the digitized spectrum. The numerator in equation (6) is the RMSD, but since RMSD is not informative on its own (it is typically larger for high intensity bands, smaller for low intensity bands), we divide the RMSD by the range of attenuation coefficients spanned by the UVvisible spectra $\left(\varepsilon_{\max }-\varepsilon_{\min }\right)$. The final \%nRMSD reported is an average from the two trials. Values of $\%$ nRMSD ranged from $0.2 \%$ to $6.0 \%$, with an average of $0.7 \%$, a first quartile of $0.4 \%$, median of $0.5 \%$, and third quartile of $0.8 \%$.

The above percentages are associated with uncertainties in the fitting process and are not errors. For instance, $f_{\text {exp,g }}$ and $f_{\text {exp }, n}$ are usually different, particularly for incomplete or overlapping bands, yielding large \%gn. A large \%gn is therefore an indicator of uncertainty (i.e., an incomplete band causes uncertainty in how to fit it). $\% \mathrm{gg}$ is also an important indicator of uncertainty; if the same band is fit differently by two different individuals, it indicates a lower confidence in the fitting. Thus, we have developed a scoring system to indicate confidence in the analytical integration. The scores are based on the four metrics listed above, with the relative weights based on the ratio of the first quartiles:

$$
\% \text { gn : \%gg : \%nn : \%nRMSD = } 1.5: 0.9: 0.5: 0.4 \approx 9: 6: 3: 2
$$

Each transition is scored out of 20 points $(9+6+3+2)$. Integer scores are assigned by deducting points for each $1 \%$ introduced in each of $\% \mathrm{gn}, \% \mathrm{gg}, \% \mathrm{nn}$, and $\% \mathrm{nRMSD}$, up to the maximum score for that category. E.g., a score of 20 is obtained if all four metrics have a value $<1 \%$. A spreadsheet is included for the score calculations in the SI (see the SI file named megatable). Molecules are categorized as "very high" confidence if the score is a perfect 20, "high" confidence for a score in the upper quartile (17-19), "medium" confidence for a score in the second quartile (12-16), "low" confidence for a in the third quartile (8-11), and "very low" confidence for a score in the lowest quartile (0-7). 


\section{RESULTS}

Out of 164 transitions, 14 scored as "very high" confidence, 29 scored as "high", 42 scored as "medium", 42 scored as "low", and 37 as "very low." A list of the 100 molecule names and solvent information (Table S1), $f_{\text {comp }}, f_{\text {exp }, g 1}, f_{\text {exp }, g 2}, f_{\text {exp }, n 1}, f_{\text {exp }, n 2}$, and scores for the 164 transitions (Table S2), and $v_{\min }, v_{\max }, \varepsilon_{\max }$, and $v$ at $\varepsilon_{\max }$ (Table S3) are included in the SI. Plain text files with the digitized UV-visible spectra, spreadsheets used for the numerical integration and gaussian deconvolution for $f_{\text {exp }, n 1}$ and $f_{\text {exp,gl }}$, ChemDraw chemical structures, and B3LYP/6-31+G*/PCM geometry-optimized structures for the 100 organic molecules are also included in the SI.
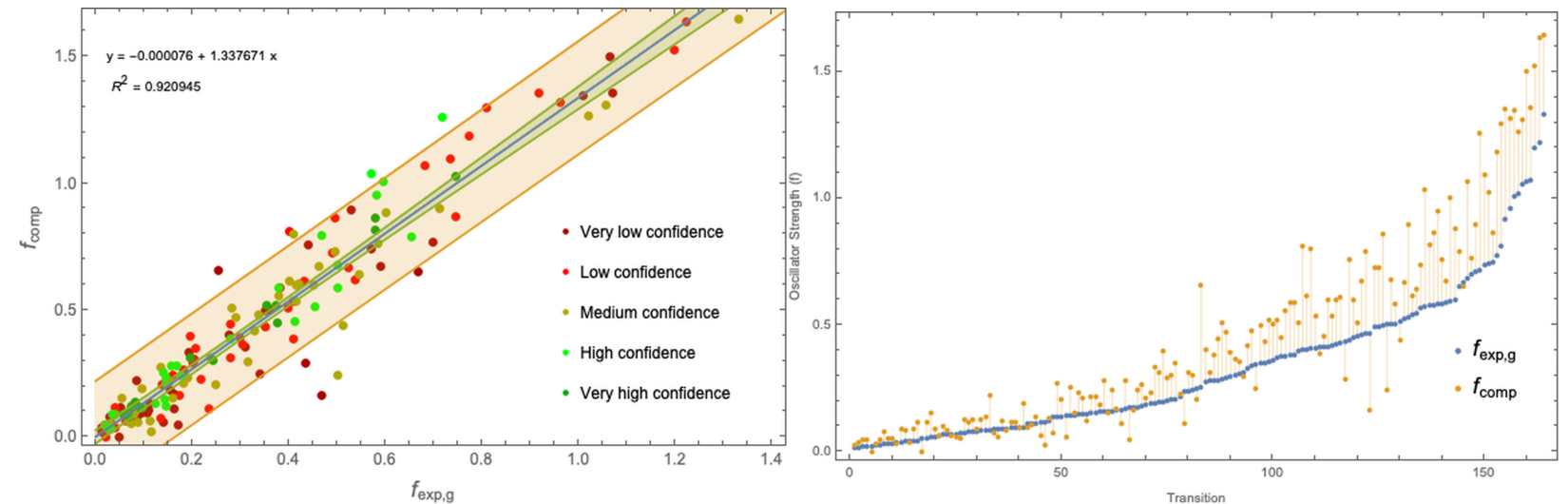

Figure 3. Left: $f_{\text {comp }}$ vs. $f_{\text {exp, },}$ for 164 transitions. The points are colored by confidence level, as indicated in the legend. The blue line is a linear regression (see comment ${ }^{56}$ ). The orange lines and area indicate $95 \%$ confidence bands for the data, while the green lines and area indicate the $95 \%$ mean confidence prediction bands. Right: $f_{\text {comp }}$ and $f_{\text {exp, } g}$ for each transition ordered by increasing strength of $f_{\text {exp,g }}$. The lines connecting the points represent the absolute differences.

Fig. 3 shows the correlation between $f_{\text {exp, }}$ and $f_{\text {comp }}$. The linear regression analysis $\left(\mathrm{R}^{2}=0.921\right)$ indicates a strong correlation between experimental and computed oscillator strengths. However, the slope of the plot (1.34) indicates a clear systematic error; The computations substantially overestimate the oscillator strength. The mean absolute error (MAE) between $f_{\text {comp }}$ and $f_{\text {exp g }}$ is 0.133 .

Some of the "very low confidence" points appear well outside of the $95 \%$ confidence intervals in Fig. 3 left. If we exclude all "very low confidence" points from the plot and the analysis, the $\mathrm{R}^{2}$ value increases to 0.935 , the slope becomes 1.354 (see SI Fig. S1), but the MAE increases slightly to 0.137 .

If plots used $\varepsilon_{\max }$ instead of $\mathrm{f}_{\text {exp,g }}$ as the reference, the $\mathrm{R}^{2}$ value for $\mathrm{f}_{\text {comp }}$ vs. $\varepsilon_{\max }$ would be 0.77 (see SI Fig. S2). Therefore, $\varepsilon_{\max }$ is correlated with $\mathrm{f}_{\text {comp }}$, as expected, but this correlation is weaker than $\mathrm{f}_{\text {comp }}$ with the area under the band. 
The large slope in Fig. 3 left (1.34) appears on the order of magnitude of a refractive index factor, since refractive indices for most common solvents are in the range of 1.3-1.5. Indeed, so far, we have assumed that the PCM solvation model employed in calculations correctly capture the effect of the solvent on the oscillator strength, and that equation (2) is a valid equation for deriving experimental oscillator strengths for a molecule in solution. The question of how to correctly account for the effect of the solvent on oscillator strength has been a topic of debate for both experiments (equation 2), and theory (equation 3). ${ }^{21-32}$ To test whether a refractive index factor improves the agreement between theory and experiment, we show in Fig. 4 the correlation between $\mathrm{n} \times f_{\text {exp,g }}$ and $f_{\text {comp }}$ (i.e., we multiply the experimentally derived oscillator strength by the refractive index $n)$.
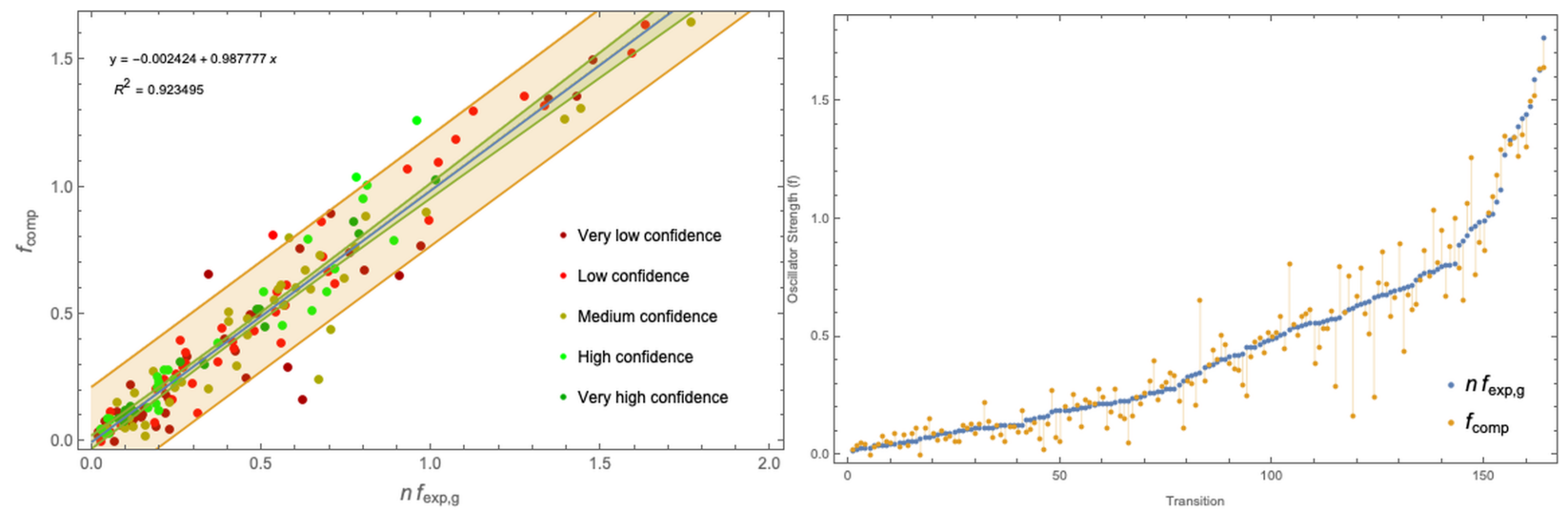

Figure 4. Left: $f_{\text {comp }}$ vs. $n \times f_{\text {exp, } g}$ for 164 transitions, where $n$ is the solvent refractive index. The points are colored by confidence level, as indicated in the legend. The blue line is a linear regression. The orange lines and area indicate $95 \%$ confidence bands for the data, while the green lines and area indicate the $95 \%$ mean confidence prediction bands. Right: $f_{\text {comp }}$ and $n \times f_{\text {exp, }}$ for each transition ordered by increasing magnitude of $n \times f_{\text {exp,g }}$. The lines connecting the points represent the absolute differences.

For $f_{\text {comp }}$ against $n \times f_{\text {exp,g }}$, the $\mathrm{R}^{2}$ increased slightly to 0.923 , but the slope (0.988) indicates a stronger quantitative agreement between computed and experimental oscillator strengths after accounting for a refractive index factor. Indeed, the MAE is reduced significantly to 0.075 . Removing "very low confidence" data (Fig. S3) improves the agreement further; without "very low confidence" points, the slope is 0.999 , The $\mathrm{R}^{2}$ is 0.937 , and the MAE is 0.069 .

On the other hand, dividing $f_{e x p, g}$ in equation (2) by $n$, as suggested in some literature, significantly reduces the agreement between computations and experimental oscillator strengths. Not only is the slope (1.808) and MAE (0.207) larger, the $\mathrm{R}^{2}$ between $f_{\text {comp }}$ and $n^{-1} \times f_{\text {exp,g }}$ also decreases (0.917), as shown in Fig. S4.

Given the structural diversity of the molecules in the OS100 set, it would be informative to 
check if certain types of molecules can account for most of the outliers. In Fig. S5, we plot the $f_{\text {exp,g }}$ vs. $f_{\text {comp }}$ and color the points according to the molecule type instead of confidence score. We find that almost half of the outliers outside the $95 \%$ confidence interval be attributed to the azo benzene derivatives. This is not surprising, since these are among the largest molecules included in the benchmark set and their transitions often involve charge transfer character. In Fig. S6, we plot $f_{\text {exp,g }}$ vs. $f_{\text {comp }}$ and color the points according to the total molecular charge. The correlation between $f_{\text {exp,g }}$ and $f_{\text {comp }}$ for charged molecules do not appear to be worse than for neutral molecules. In fact, most of the outliers outside the $95 \%$ confidence interval are neutral molecules.

\section{CONCLUSIONS}

Using a benchmark set of 164 transitions from 100 molecules, we have compared quantum chemically computed oscillator strengths with oscillator strengths we derived from experimental UV-visible absorption spectra. Using equation (2) to obtain experimental oscillator strengths, the discrepancy between experimental and computed oscillator strengths is large (slope 1.34). One reason for this discrepancy could be the refractive index. Reports in the literature disagree on how equations (2) and (3) must be modified for absorption of molecules in solvent. ${ }^{16-32}$ Our benchmark cannot conclusively resolve this debate, although the discrepancy between experiments and computations can be largely reconciled by a factor of $n$ (either multiplying $\mathrm{f}_{\text {exp,g }}$ by $n$ or dividing $f_{\text {comp }}$ as computed in the TD-DFT IEF-PCM non-equilibrium linear response formalism ${ }^{43,49}$ by $n$ ). This conclusion would be better supported through continued benchmarking, such as by expanding this benchmark set to include additional "high" and "very high" confidence data and performing additional computations to determine the sensitivity of the $f_{\text {comp }}$ and $f_{\text {exp }, g}$ plot on the quantum chemical level of theory used.

An important next step would be to quantify the accuracy of continuum or explicit solvent models in predicting solvent effects oscillator strengths. ${ }^{57}$ Both implicit and explicit models appear to successfully predict trends in oscillator strengths for the same molecule in different environments, ${ }^{58,59}$ but it is not yet clear if such predictions are quantitative. Preparing a benchmark set of experimental oscillator strengths gas-phase UV-visible spectra would also be valuable towards this end, but it is also more challenging since gas-phase spectra tend to have well-resolved vibronic transitions that are difficult to fit accurately.

Finally, while one way to compare experiments and theory directly is by deriving easily 
computable quantities from experimental data, as done in this work, another approach is to continue to develop computational methods that simulate realistic spectra through combined quantum and (semi-)classical methods or machine learning approaches. ${ }^{60-68}$ To aid in benchmarking for such efforts, we have provided the digitized UV-visible data and optimized molecular geometries for the 100 molecules in the SI.

\section{SUPPORTING INFORMATION}

- Supporting.pdf: Information about the 100 molecules in the OS100 set and the solvent

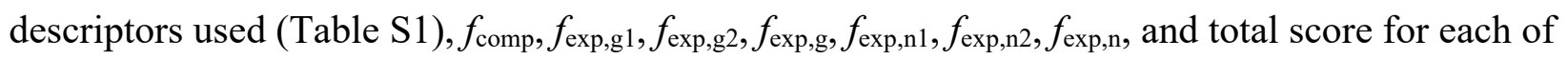
the 164 transitions (Table S2), $v_{\min }, v_{\max }, \varepsilon_{\max }$, and $\mathrm{v}$ at $\varepsilon_{\max }$ for each of the 164 transitions (Table S3), plot and linear regression for $f_{\text {comp }}$ vs. $f_{\text {exp,g }}$ after excluding 37 "very low confidence" points (Fig. S1), plot and linear regression for $f_{\text {comp }}$ Vs. $\varepsilon_{\max }$ (Fig. S2), plot and linear regression for $f_{\text {comp }}$ vs. $n \times f_{\text {exp,g }}$ after excluding 37 "very low confidence" points (Fig. S3), plots and linear regression for $f_{\text {comp }}$ vs. $n^{-1} \times f_{\text {exp,g, }}$, plots and linear regression for $\mathrm{f}_{\text {comp }} \mathrm{vs}$. $\mathrm{f}_{\text {exp,g }}$ colored by molecule type (Fig. S5) and total molecule charge (Fig. S6).

- Supporting.zip: SIplots.pdf, with plots and deconvolutions of all digitized spectra for the $f_{\text {exp,g1 }}$ data, chemical structures, and TD-B3LYP/6-31+G* stick spectra, ChemDraw Structures for the 100 molecules, Excel files of digitized spectra where numerical and Gaussian fitting was

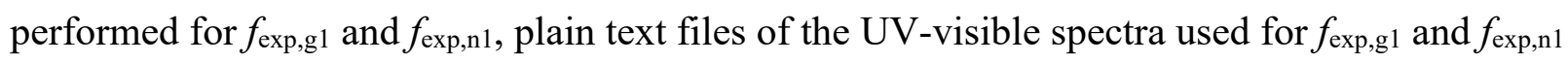
data, B3LYP/6-31+G*/PCM geometry-optimized structures for the 100 molecules, tables S1, S2,

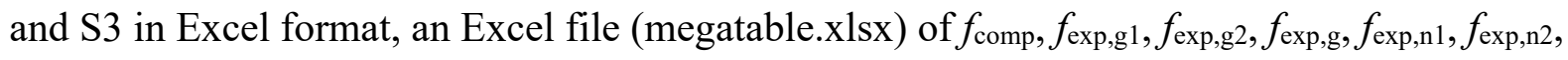
and $f_{\text {exp,n, }}$, digitization and fitting statistics, sources of uncertainty, and scoring functions.

\section{ACKNOWLEDGEMENTS}

The idea for this project began after a discussion with Prof. Gregory Poon. Emrah Trumic, Andy Nguyen, and Audi Jeter aided in the selection and preliminary digitizing/fitting of UVvisible spectra for inclusion in earlier versions of the OS100 set. S.G. acknowledges NSF XSEDE for computational resources from Research Allocation CHE180027. We also acknowledge the use of Georgia State University's research computing resources ${ }^{69}, 70$ that are supported by Georgia State's Research Solutions. S.G. acknowledges the donors of the American Chemical Society Petroleum Research Fund for support through PRF\# 60837-DNI6. This material is in part based 
upon work supported by the National Science Foundation (NSF) under Grant CHE-2047667.

\section{Declaration of competing financial interests}

The authors declare no competing financial interests.

\section{REFERENCES}

1. Beer, A., Bestimmung Der Absorption Des Rothen Lichts in Farbigen Flussigkeiten. Ann. Physik. 1852, 162, 78-88.

2. $\quad$ Laurent, A. D.; Jacquemin, D., Td-Dft Benchmarks: A Review. Int. J. Quantum Chem. 2013, 113 (17), 20192039.

3. Jacquemin, D.; Wathelet, V.; Perpete, E. A.; Adamo, C., Extensive Td-Dft Benchmark: Singlet-Excited States of Organic Molecules. J Chem Theory Comput 2009, 5 (9), 2420-35.

4. Loos, P. F.; Galland, N.; Jacquemin, D., Theoretical 0-0 Energies with Chemical Accuracy. J. Phys. Chem. Lett. 2018, 9 (16), 4646-4651.

5. Santoro, F.; Jacquemin, D., Going Beyond the Vertical Approximation with Time-Dependent Density Functional Theory. Wiley Interdiscip. Rev. Comput. Mol. Sci. 2016, 6 (5), 460-486.

6. Gozem, S.; Krylov, A. I., The Ezspectra Suite: An Easy-to-Use Toolkit for Spectroscopy Modeling. Wiley Interdiscip. Rev. Comput. Mol. Sci. 2021, e1546.

7. Liu, X.; Xu, Z.; Cole, J. M., Molecular Design of Uv-Vis Absorption and Emission Properties in Organic Fluorophores: Toward Larger Bathochromic Shifts, Enhanced Molar Extinction Coefficients, and Greater Stokes Shifts. J. Phys. Chem. C 2013, 117 (32), 16584-16595.

8. Lee, Y.; Jo, A.; Park, S. B., Rational Improvement of Molar Absorptivity Guided by Oscillator Strength: A Case Study with Furoindolizine-Based Core Skeleton. Angew Chem Int Ed Engl 2015, 54 (52), 15689-93.

9. Wang, J.; Cong, S.; Wen, S.; Yan, L.; Su, Z., A Rational Design for Dye Sensitizer: Density Functional Theory Study on the Electronic Absorption Spectra of Organoimido-Substituted Hexamolybdates. J. Phys. Chem. C 2013, 117 (5), 2245-2251.

10. Beard, E. J.; Sivaraman, G.; Vazquez-Mayagoitia, A.; Vishwanath, V.; Cole, J. M., Comparative Dataset of Experimental and Computational Attributes of Uv/Vis Absorption Spectra. Sci. Data 2019, 6 (1), 307.

11. Chen, X. K.; Tsuchiya, Y.; Ishikawa, Y.; Zhong, C.; Adachi, C.; Bredas, J. L., A New Design Strategy for Efficient Thermally Activated Delayed Fluorescence Organic Emitters: From Twisted to Planar Structures. $A d v$. Mater 2017, 29 (46).

12. Hollas, J. M., Modern Spectroscopy. Fourth Edition ed.; John Wiley \& Sons: 2004; p 27-39.

13. Myers, A. B., Molecular Electronic Spectral Broadening in Liquids and Glasses. Annu. Rev. Phys. Chem. 1998, $49,267-95$

14. Turro, N. J.; Ramamurthy, V.; Ramamurthy, V.; Scaiano, J. C., Principles of Molecular Photochemistry: An Introduction. University science books: 2009; p 169-262.

15. Hilborn, R. C., Einstein Coefficients, Cross Sections, F Values, Dipole Moments, and All That. Am. J. Phys. 1982, 50 (11), 982-986.

16. Chako, N. Q., Absorption of Light in Organic Compounds. J. Chem. Phys. 1934, 2 (10), 644-653.

17. Myers, A. B.; Birge, R. R., The Effect of Solvent Environment on Molecular Electronic Oscillator Strengths. $J$. Chem. Phys. 1980, 73 (10), 5314-5321.

18. Birge, R. R., Reply to Abe's Comments on "the Effect of Solvent Environment on Molecular Electronic Oscillator Strengths"'[Ab Myers and Rr Birge, J. Chem. Phys. 7 3, 5314 (1980)]. J Chem Phys 1982, 77 (2), 1075-1076.

19. Mohanty, J.; Nau, W. M., Refractive Index Effects on the Oscillator Strength and Radiative Decay Rate of 2,3Diazabicyclo[2.2.2] Oct-2-Ene. Photochem. Photobiol. Sci. 2004, 3 (11-12), 1026-31.

20. Morris, J. V.; Mahaney, M. A.; Huber, J. R., Fluorescence Quantum Yield Determinations. 9, 10Diphenylanthracene as a Reference Standard in Different Solvents. J. Phys. Chem. 1976, 80 (9), 969-974.

21. Abe, T., Theory of Solvent Effects on Oscillator Strengths for Molecular Electronic Transitions. Bull. Chem. Soc. Jpn. 1970, 43 (3), 625-628. 
22. Abe, T., Comments on "the Effect of Solvent Environment on Molecular Electronic Oscillator Strengths". $J$. Chem. Phys. 1982, 77 (2), 1074-1074.

23. Iweibo, I.; Oderinde, R.; Faniran, J., Electronic Absorption Spectra and Structures of Aniline and Its 4-Chloro, Pentafluoro and Pentachloro Derivatives. Spectrochim. Acta A 1982, 38 (1), 1-7.

24. Jinnouchi, Y.; Kohno, M.; Kuboyama, A., Solvent Effects on the Intensity of the N $\pi^{*}$ Absorption Spectra of 1Phenylethylenetrithiocarbonate and P-Benzoquinones. Bull. Chem. Soc. Jpn. 1984, 57 (4), 1147-1148.

25. Sklar, A. L., Electronic Absorption Spectra of Benzene and Its Derivatives. Rev. Mod. Phys. 1942, 14 (2-3), 232.

26. Mulliken, R. S.; Rieke, C. A., Molecular Electronic Spectra, Dispersion and Polarization: The Theoretical Interpretation and Computation of Oscillator Strengths and Intensities. Rep. Prog. Phys. 1941, 8 (1), 231.

27. Hare, P. M.; Price, E. A.; Stanisky, C. M.; Janik, I.; Bartels, D. M., Solvated Electron Extinction Coefficient and Oscillator Strength in High Temperature Water. J. Phys. Chem. A 2010, 114 (4), 1766-1775.

28. Shibuya, T.-i., The Refractive-Index Correction to the Radiative Rate Constant. Chem. Phys. Lett. 1983, 103 (1), 46-48.

29. Hirayama, S.; Phillips, D., Correction for Refractive Index in the Comparison of Radiative Lifetimes in Vapour and Solution Phases. J. Photochem. 1980, 12 (2), 139-145.

30. Abe, T.; Iweibo, I., The Experimental and Theoretical Expressions for the Molecular Electronic Oscillator Strength in Solution. J. Chem. Phys. 1985, 83 (4), 1546-1550.

31. Shibuya, T. i., A Dielectric Model for the Solvent Effect on the Intensity of Light Absorption. J. Chem. Phys. 1983, $78(8), 5175-5182$.

32. Dexter, D., Absorption of Light by Atoms in Solids. Phys. Rev. 1956, 101 (1), 48.

33. Sarkar, R.; Boggio-Pasqua, M.; Loos, P. F.; Jacquemin, D., Benchmarking Td-Dft and Wave Function Methods for Oscillator Strengths and Excited-State Dipole Moments. J Chem Theory Comput 2021, 17 (2), 1117-1132.

34. Chrayteh, A.; Blondel, A.; Loos, P. F.; Jacquemin, D., Mountaineering Strategy to Excited States: Highly Accurate Oscillator Strengths and Dipole Moments of Small Molecules. J. Chem. Theory Comput. 2021, 17 (1), 416-438.

35. Jacquemin, D.; Duchemin, I.; Blondel, A.; Blase, X., Assessment of the Accuracy of the Bethe-Salpeter (Bse/Gw) Oscillator Strengths. J Chem Theory Comput 2016, 12 (8), 3969-81.

36. Labhart, H., Zur Quantitativen Beschreibung Des Einflusses Von Substituenten Auf Das Absorptionsspektrum Ebener Molekeln. Anwendung Auf Anthrachinon. Helv. Chim. Acta. 1957, 40 (5), 1410-1420.

37. van Setten, M. J.; Caruso, F.; Sharifzadeh, S.; Ren, X.; Scheffler, M.; Liu, F.; Lischner, J.; Lin, L.; Deslippe, J. R.; Louie, S. G., Gw 100: Benchmarking G 0 W 0 for Molecular Systems. J. Chem. Theory Comput. 2015, 11 (12), 5665-5687.

38. Uv Atlas of Organic Compounds. Springer US: Boston, MA, 1967; p 5-605.

39. Becke, A. D., Density-Functional Exchange-Energy Approximation with Correct Asymptotic Behavior. Phys. Rev. A 1988, 38 (6), 3098.

40. Lee, C.; Yang, W.; Parr, R. G., Development of the Colle-Salvetti Correlation-Energy Formula into a Functional of the Electron Density. Phys. Rev. B 1988, 37 (2), 785.

41. Miertuš, S.; Scrocco, E.; Tomasi, J., Electrostatic Interaction of a Solute with a Continuum. A Direct Utilizaion of Ab Initio Molecular Potentials for the Prevision of Solvent Effects. Chem. Phys. 1981, 55 (1), 117-129.

42. Winget, P.; Dolney, D. M.; Giesen, D. J.; Cramer, C. J.; Truhlar, D. G., Minnesota Solvent Descriptor Database. Minneapolis, MN: Department of Chemistry and Supercomputer Institute 1999.

43. Cossi, M.; Barone, V., Time-Dependent Density Functional Theory for Molecules in Liquid Solutions. J. Chem. Phys. 2001, 115 (10), 4708-4717.

44. Marin, F.; Rohatgi, A.; Charlot, S., Webplotdigitizer, a Polyvalent and Free Software to Extract Spectra from Old Astronomical Publications: Application to Ultraviolet Spectropolarimetry. arXiv preprint arXiv:1708.02025 2017.

45. Harris, D. C., Nonlinear Least-Squares Curve Fitting with Microsoft Excel Solver. J. Chem. Ed. 1998, 75 (1), 119.

46. Wolfram Research, Inc., Mathematica, Version 12.3.1; Champaign, Illinois, 2021.

47. Bouman, T. D.; Hansen, A. E.; Voigt, B.; Rettrup, S., Large-Scale Rpa Calculations of Chiroptical Properties of Organic Molecules: Program Rpac. Int. J. Quantum Chem. 1983, 23 (2), 595-611.

48. Epifanovsky, E.; Gilbert, A. T.; Feng, X.; Lee, J.; Mao, Y.; Mardirossian, N.; Pokhilko, P.; White, A. F.; Coons, M. P.; Dempwolff, A. L., Software for the Frontiers of Quantum Chemistry: An Overview of Developments in the Q-Chem 5 Package. J. Chem. Phys. 2021, 155 (8), 084801.

49. Frisch, M. J.; Trucks, G. W.; Schlegel, H. B.; Scuseria, G. E.; Robb, M. A.; Cheeseman, J. R.; Scalmani, G.; Barone, V.; Petersson, G. A.; Nakatsuji, H., et al. Gaussian 16 Rev. C.01, Wallingford, CT, 2016. 
50. Reule, A., Errors in Spectrophotometry and Calibration Procedures to Avoid Them. J. Res. Natl. Inst. Stand. Technol. A 1976, 80 (4), 609.

51. Mayerhöfer, T. G.; Pahlow, S.; Popp, J., The Bouguer-Beer-Lambert Law: Shining Light on the Obscure. ChemPhysChem 2020, 21 (18), 2029.

52. Chan, W.; Cooper, G.; Brion, C., Absolute Optical Oscillator Strengths for the Electronic Excitation of Atoms at High Resolution: Experimental Methods and Measurements for Helium. Phys. Rev. A 1991, 44 (1), 186.

53. Chan, W.; Cooper, G.; Brion, C., The Electronic Spectrum of Water in the Discrete and Continuum Regions. Absolute Optical Oscillator Strengths for Photoabsorption (6-200 Ev). Chem. Phys. 1993, 178 (1-3), 387-400.

54. Mata, R. A.; Suhm, M. A., Benchmarking Quantum Chemical Methods: Are We Heading in the Right Direction? Angew. Chem. Int. Ed. Engl. 2017, 56 (37), 11011-11018.

55. Condon, E., A Theory of Intensity Distribution in Band Systems. Phys. Rev. 1926, 28 (6), 1182.

56. Linear regression could also be performed while forcing the y-intercept equal to zero, which is well justified in this case (the y-intercept in the linear regression is indeed small). Linear regression without a constant would yield a slope of 1.3375 and $\mathrm{R}^{\wedge} 2=0.9651$. The improved $\mathrm{R}^{\wedge} 2$ is not an indication of a better fit; setting the $\mathrm{y}$ intercept to 0 results in the use of a different null model for computing $\mathrm{R}^{\wedge} 2$, and $\mathrm{R}^{\wedge} 2$ computed with and without a y-intercept cannot be compared directly. We have opted to keep the y-intercept unconstrained for the linear regressions in this work because it employs the more widely recognized definition of $\mathrm{R}^{\wedge} 2$, even if this yields a lower apparent $\mathrm{R}^{\wedge} 2$.

57. Herbert, J. M., Dielectric Continuum Methods for Quantum Chemistry. WIREs Comp. Mol. Sci 2021, 11 (4), e1519.

58. Dratch, B. D.; Orozco-Gonzalez, Y.; Gadda, G.; Gozem, S., Ionic Atmosphere Effect on the Absorption Spectrum of a Flavoprotein: A Reminder to Consider Solution Ions. J. Phys. Chem. Lett. 2021, 12 (34), 83848396.

59. Kabir, M. P.; Orozco-Gonzalez, Y.; Gozem, S., Electronic Spectra of Flavin in Different Redox and Protonation States: A Computational Perspective on the Effect of the Electrostatic Environment. Phys. Chem. Chem. Phys. 2019, 21 (30), 16526-16537.

60. Crespo-Otero, R.; Barbatti, M., Spectrum Simulation and Decomposition with Nuclear Ensemble: Formal Derivation and Application to Benzene, Furan and 2-Phenylfuran. In Marco Antonio Chaer Nascimento, Springer: 2014; pp 89-102.

61. Petrenko, T.; Neese, F., Analysis and Prediction of Absorption Band Shapes, Fluorescence Band Shapes, Resonance Raman Intensities, and Excitation Profiles Using the Time-Dependent Theory of Electronic Spectroscopy. J. Chem. Phys. 2007, 127 (16), 164319.

62. Borrego-Sánchez, A.; Zemmouche, M.; Carmona-García, J.; Francés-Monerris, A.; Mulet, P.; Navizet, I.; Roca-Sanjuán, D., Multiconfigurational Quantum Chemistry Determinations of Absorption Cross Sections $(\Sigma)$ in the Gas Phase and Molar Extinction Coefficients (E) in Aqueous Solution and Air-Water Interface. J Chem Theory Comput 2021, 17 (6), 3571-3582.

63. Cerezo, J.; Avila Ferrer, F. J.; Prampolini, G.; Santoro, F., Modeling Solvent Broadening on the Vibronic Spectra of a Series of Coumarin Dyes. From Implicit to Explicit Solvent Models. J. Chem. Theory Comput. 2015, 11 (12), 5810-25.

64. Ončák, M.; Šištík, L.; Slavíček, P., Can Theory Quantitatively Model Stratospheric Photolysis? Ab Initio Estimate of Absolute Absorption Cross Sections of Cloocl. J. Chem. Phys. 2010, 133 (17), 174303.

65. Zutterman, F.; Liégeois, V.; Champagne, B., Simulation of the Uv/Visible Absorption Spectra of Fluorescent Protein Chromophore Models. ChemPhotoChem 2017, 1 (6), 281-296.

66. Xue, B.-X.; Barbatti, M.; Dral, P. O., Machine Learning for Absorption Cross Sections. J. Phys. Chem. A 2020, 124 (35), 7199-7210.

67. Dral, P. O.; Barbatti, M., Molecular Excited States through a Machine Learning Lens. Nat. Rev. Chem. 2021, 5 (6), 388-405.

68. Zuehlsdorff, T. J.; Isborn, C. M., Modeling Absorption Spectra of Molecules in Solution. Int. J. Quantum Chem. 2019, $119(1)$, e25719.

69. Sarajlic, S.; Edirisinghe, N.; Lukinov, Y.; Walters, M.; Davis, B.; Faroux, G. In Orion: Discovery Environment for Hpc Research and Bridging Xsede Resources, Proceedings of the XSEDE16 Conference on Diversity, Big Data, and Science at Scale, 2016; pp 1-5.

70. Sarajlic, S.; Edirisinghe, N.; Wu, Y.; Jiang, Y.; Faroux, G., Training-Based Workforce Development in Advanced Computing for Research and Education (Acore). In Proceedings of the Practice and Experience in Advanced Research Computing 2017 on Sustainability, Success and Impact, 2017; pp 1-4. 


\title{
Supporting Information for:
}

\section{OS100: A Benchmark Set of 100 Digitized UV-Visible Spectra and Derived Experimental Oscillator Strengths}

\author{
Astrid S. Tarleton ${ }^{\mathrm{a}}$, Jorge Garcia-Alvarez ${ }^{\mathrm{a}}$, Anah Wynn ${ }^{\mathrm{a}}$, Cade Awbrey ${ }^{\mathrm{a}}$, Tomas Roberts ${ }^{\mathrm{a}}$, \\ Samer Gozem ${ }^{\mathrm{a}^{*}}$
}

${ }^{a}$ Department of Chemistry, Georgia State University, Atlanta, GA 30302, United States.

\section{Contents:}

Tables S1: Information about the 100 molecules in the OS100 set and their solvent information.

Tables S2: $f_{\text {comp }}, f_{\text {exp,g1 }}, f_{\text {exp,g2 }}, f_{\text {exp, },}, f_{\text {exp,n1 }}, f_{\text {exp, n2 }}, f_{\text {exp,n }}$, and total score for each of the 164 transitions.

Tables S3: $\mathrm{v}_{\min }, \mathrm{v}_{\max }, \varepsilon_{\max }$, and $\mathrm{v}$ at $\varepsilon_{\max }$ for each of the 164 transitions.

Fig. S1: Plot and linear regression for $f_{\text {comp }}$ vs. $f_{\text {exp }, g}$ after excluding 37 "very low confidence" points.

Fig. S2: Plot and linear regression for $f_{\text {comp }}$ vs. $\varepsilon_{\text {max }}$.

Fig. S3: Plot and linear regression for $f_{\text {comp }}$ vs. $n \times f_{\text {exp,g }}$ after excluding 37 "very low confidence" points.

Fig. S4: Plots and linear regression for $f_{\text {comp }}$ vs. $n^{-1} \times f_{\text {exp g. }}$.

Fig. S5: Plot and linear regression for $f_{\text {comp }}$ vs. $f_{\text {exp,g }}$ colored by molecule type.

Fig. S6: Plot and linear regression for $f_{\text {comp }}$ vs. $f_{\text {exp,g }}$ colored by total molecule charge.

\section{Additional Supporting Files}

A Supporting.zip file containing the following:

- A pdf file (SIplots.pdf) with plots and deconvolutions of all digitized spectra for the $f_{\text {exp.g1 }}$ data, chemical structures, and TD-B3LYP/6-31+G* stick spectra.

- ChemDraw Structures for the 100 molecules.

- Excel files of digitized spectra where numerical and Gaussian fitting was performed for $f_{\text {exp,g1 }}$ and $f_{\text {exp,n1 }}$.

- Plain text files of the UV-visible spectra used for $f_{\text {exp.g1 }}$ and $f_{\text {exp,n1 }}$ data.

- B3LYP/6-31+G*/PCM geometry-optimized structures for the 100 molecules.

- Tables S1, S2, and S3 in Excel format.

- An Excel file (megatable.xlsx) of $f_{\text {comp }}, f_{\text {exp,g1 } 1}, f_{\text {exp,g2 }}, f_{\text {exp.g },}, f_{\text {exp,n1 } 1}, f_{\text {exp,n2 }}$, and $f_{\text {exp,n }}$, digitization and fitting statistics, sources of uncertainty, and scoring functions. 
Table S1: 100 molecules for which UV-visible spectra are digitized and processed in this work. The original spectra were all obtained from the UV Atlas of Organic Compounds. ${ }^{1}$ The molecules are assigned IDs from 000-099 which are used throughout the rest of the supporting information. The table includes the chemical names, reference IDs from Ref. 1, solvent in which the spectra were obtained, solvent dielectric, and solvent refractive indices at $20^{\circ} \mathrm{C}$. The solvent dielectric constants and refractive indices were obtained from the Minnesota Solvent Descriptor Database. ${ }^{2}$

\begin{tabular}{|c|c|c|c|c|c|}
\hline ID & Molecule name & Reference $^{1}$ & Solvent & $\begin{array}{l}\text { Solvent } \\
\text { Dielectric }\end{array}$ & $\begin{array}{l}\text { Refractive } \\
\text { Index (n) }\end{array}$ \\
\hline 000 & cis -1, 2-Dichloroethylene & $\mathrm{A} 1 / 4$ & Heptane & 1.9113 & 1.3878 \\
\hline 001 & trans-1,2-Dichloroethylene & $\mathrm{A} 1 / 5$ & Heptane & 1.9113 & 1.3878 \\
\hline 002 & Trichloroethylene & $\mathrm{A} 1 / 6$ & Heptane & 1.9113 & 1.3878 \\
\hline 003 & Tetrachloroethylene & $\mathrm{A} 1 / 7$ & Heptane & 1.9113 & 1.3878 \\
\hline 004 & Penta-1,3-diene & $\mathrm{A} 3 / 1$ & Heptane & 1.9113 & 1.3878 \\
\hline 005 & 2,5-dimethylhexa-2,4-diene & $\mathrm{A} 3 / 2$ & Heptane & 1.9113 & 1.3878 \\
\hline 006 & Cycloocta-1,3-diene & $\mathrm{A} 3 / 4$ & Hexane & 1.8819 & 1.3749 \\
\hline 007 & 1-(cyclohexen-1-yl)cyclohexene & $\mathrm{A} 3 / 5$ & Heptane & 1.9113 & 1.3878 \\
\hline 008 & cis-Hex-3-en-1-yne & $\mathrm{A} 4 / 1$ & Ethanol & 24.852 & 1.3611 \\
\hline 009 & trans-Hex-3-en-1-yne & $\mathrm{A} 4 / 2$ & Ethanol & 24.852 & 1.3611 \\
\hline 010 & 1,6-Dihydroazulene & $\mathrm{A} 15 / 3$ & Hexane & 1.8819 & 1.3749 \\
\hline 011 & p-Benzoquinone & $\mathrm{B} 8 / 23$ & Hexane & 1.8819 & 1.3749 \\
\hline 012 & Hydroxy-p-benzoquinone & $\mathrm{B} 8 / 24$ & $\mathrm{CCl} 4$ & 2.228 & 1.4601 \\
\hline 013 & Methoxy-p-benzoquinone & $\mathrm{B} 8 / 25$ & Hexane & 1.8819 & 1.3749 \\
\hline 014 & 2-Sulfinylhexahydro-1,3-benzodithiole & $\mathrm{B} 16 / 3$ & Ethanol & 24.852 & 1.3611 \\
\hline 015 & Thiourea & $\mathrm{B} 17 / 6$ & Water & 78.355 & 1.3328 \\
\hline 016 & S-ethyl thioacetate & $\mathrm{B} 21 / 1$ & Heptane & 1.9113 & 1.3878 \\
\hline 017 & Nitromethane & $\mathrm{C} 4 / 1$ & Hexane & 1.8819 & 1.3749 \\
\hline 018 & t-Butyl nitrite & $\mathrm{C} 4 / 3$ & Hexane & 1.8819 & 1.3749 \\
\hline 019 & Isopentyl nitrite & $\mathrm{C} 4 / 4$ & Hexane & 1.8819 & 1.3749 \\
\hline 020 & N-Benzylideneaniline & $\mathrm{c} 6 / 1$ & Ethanol & 24.852 & 1.3611 \\
\hline 021 & 4- Nitro-N-benzylideneaniline & $\mathrm{C} 6 / 2$ & Ethanol & 24.852 & 1.3611 \\
\hline 022 & N-Benzylidene-4-dimethylaminoaniline & $\mathrm{C} 6 / 3$ & Ethanol & 24.852 & 1.3611 \\
\hline 023 & Tetramethylazodicarboxamide & $\mathrm{C} 7 / 2$ & Dioxane & 2.2099 & 1.4224 \\
\hline 024 & Phenylazoformate (anion) & $\mathrm{C} 7 / 3$ & Ethanol & 24.852 & 1.3611 \\
\hline 025 & Dimethyl [(E)-phenyldiazenyl]phosphonate & $V 7 / 4$ & Dioxane & 2.2099 & 1.4224 \\
\hline 026 & trans-Azobenzene & $\mathrm{C} 7 / 5$ & Hexane & 1.8819 & 1.3749 \\
\hline 027 & 4-(Dimethylamino)azobenzene (cation) & $\mathrm{C} 7 / 7$ & $\mathrm{H} 2 \mathrm{SO} 4(\mathrm{aq})$ & 78.355 & 1.3328 \\
\hline 028 & 4-Dimethylamino-4'--nitroazobenzene & $\mathrm{C} 7 / 8$ & Ethanol & 24.852 & 1.3611 \\
\hline 029 & 1-Ethyl-2-(phenylazo)-pyridinium (cation) & $\mathrm{C} 7 / 10$ & Acetonitrile & 35.688 & 1.3442 \\
\hline 030 & 1-Phenyl-2-(phenylthio)diazene & $\mathrm{C} 7 / 12$ & Dioxane & 2.2099 & 1.4224 \\
\hline 031 & 1-Phenyl-2-(phenylsulfonyl)diazene & $\mathrm{C} 7 / 13$ & Dioxane & 2.2099 & 1.4224 \\
\hline 032 & $\mathrm{~N}, \mathrm{~N}, \mathrm{~N}^{\prime}, \mathrm{N}^{\prime}$-Tetramethylformamidinium (cation) & $\mathrm{C} 8 / 1$ & Ethanol & 24.852 & 1.3611 \\
\hline 033 & $\mathrm{~N}$-[3-(Dimethylamino)allylidene]-N-methylmethanaminium (cation) & $\mathrm{C} 8 / 2$ & Ethanol & 24.852 & 1.3611 \\
\hline 034 & 2,4-Cyclopentadien-1-ylidenehydrazine & $\mathrm{C} 9 / 1$ & Hexane & 1.8819 & 1.3749 \\
\hline 035 & Cyclohexanone semicarbazone & $\mathrm{C} 9 / 2$ & Ethanol & 24.852 & 1.3611 \\
\hline 036 & 1-Isopropylidene-2-p-nitrophenyl-hydrazine & $\mathrm{c} 9 / 3$ & Ethanol & 24.852 & 1.3611 \\
\hline 037 & 1-Ethylidene-2-(2,4-dinitrophenyl)-hydrazine & $\mathrm{c} 9 / 4$ & $\mathrm{CHCl3/Ethanol}$ & 24.852 & 1.3611 \\
\hline 038 & 1-Ethylidene-2-(2,4-dinitrophenyl)-hydrazone (anion) & $\mathrm{C} 9 / 5$ & $\mathrm{CHCl}$ /Ethanol & 24.852 & 1.3611 \\
\hline 039 & Crotonaldehyde 2,4-dinitrophenylhydrazone & $\mathrm{c} 9 / 6$ & $\mathrm{CHCl} /$ Ethanol & 24.852 & 1.3611 \\
\hline 040 & N,N'-Di(2-hydroxybenzylidene)hydrazine & $\mathrm{c} 9 / 10$ & Methanol & 32.613 & 1.3288 \\
\hline 041 & o-Xylene & $\mathrm{D} 2 / 5$ & Heptane & 1.9113 & 1.3878 \\
\hline 042 & m-Xylene & $\mathrm{D} 2 / 6$ & Heptane & 1.9113 & 1.3878 \\
\hline 043 & p-Xylene & $\mathrm{D} 2 / 7$ & Heptane & 1.9113 & 1.3878 \\
\hline 044 & 2,3,5,6,7,8-hexahydro-1H-benz(f)indene & D3/5 & Petroleum Ether & 1.89 & 1.3715 \\
\hline 045 & $1,2,3,4,5,6,7,8$-octahydroanthracene & D3/6 & Petroleum Ether & 1.89 & 1.3715 \\
\hline 046 & Phenol & D5/5 & Water & 78.355 & 1.3328 \\
\hline
\end{tabular}




\begin{tabular}{|c|c|}
\hline 047 & Phenolate (anion) \\
\hline 048 & $\mathrm{~N}, \mathrm{~N}$-Diethylaniline \\
\hline 049 & Nitrobenzene \\
\hline 050 & o-Chlorotoluene \\
\hline 051 & $\mathrm{p}$-Chlorotoluene \\
\hline 052 & p-Bromofluorobenzene \\
\hline 053 & o-Nitrophenol \\
\hline 054 & m-Nitrophenol \\
\hline 055 & p-Nitrophenol \\
\hline 056 & p-Nitrophenolate (anion) \\
\hline 057 & o-Acetylphenol \\
\hline 058 & o-Methoxyacetophenone \\
\hline 059 & o-Hydroxybenzaldehyde \\
\hline 060 & o-Methoxybenzaldehyde \\
\hline 061 & o-Aminobenzaldehyde \\
\hline 062 & p-Hydroxybenzaldehyde \\
\hline 063 & p-Dimethylaminobenzaldehyde \\
\hline 064 & p-Cyanobenzaldehyde \\
\hline 065 & Hydrogen phthalate (anion) \\
\hline 066 & p-Nitrophenylhydrazine \\
\hline 067 & 2,3-Dimethylphenolate (anion) \\
\hline 068 & 4-Methyl-2-nitroaniline \\
\hline 069 & Cinnamaldehyde \\
\hline 070 & Benzylideneacetone \\
\hline 071 & Benzophenone \\
\hline 072 & 4-Methylbenzophenone \\
\hline 073 & 4-Aminobenzophenone \\
\hline 074 & 4-(N,N-Dimethylamino)-benzophenone \\
\hline 075 & 4-Hydroxybenzophenone \\
\hline 076 & Diphenylamine \\
\hline 077 & 2-Nitrodiphenylamine \\
\hline 078 & 4-Nitrodiphenylamine \\
\hline 079 & Thiobenzophenone \\
\hline 080 & 1-Naphthol \\
\hline 081 & 1-Naphtholate (anion) \\
\hline 082 & 2-Naphtholate (anion) \\
\hline 083 & 1-Naphthoic acid \\
\hline 084 & 2-Naphthaldehyde \\
\hline 085 & 1,5-Dinitronaphthalene \\
\hline 086 & Thiazole \\
\hline 087 & 2-Mercaptothiazole \\
\hline 088 & Pyridinium (cation) \\
\hline 089 & 2-Methoxypyridine \\
\hline 090 & 2-Chloro-6-ethoxypyridine \\
\hline 091 & cis-1,2-Di-(3'-pyridyl)ethylene \\
\hline 092 & Deprotonated 2-Hydroxyquinoline (anion) \\
\hline 093 & 4-Hydroxyquinolynium (cation) \\
\hline 094 & Deprotonated 4-Hydroxyquinoline (anion) \\
\hline 095 & 5-Hydroxyquinoline \\
\hline 096 & 5-Hydroxyquinolynium (cation) \\
\hline 097 & Deprotonated 5-Hydroxyquinoline (anion) \\
\hline 098 & 3-Hydroxyphthalamide \\
\hline 099 & 3-Amino-1-methylphthalamide \\
\hline
\end{tabular}

\begin{tabular}{|c|c|c|c|}
\hline $\mathrm{D} 5 / 6$ & $\mathrm{NaOH}(\mathrm{aq})$ & 78.355 & 1.3328 \\
\hline $\mathrm{D} 6 / 2$ & Heptane & 1.9113 & 1.3878 \\
\hline $\mathrm{D} 8 / 6$ & Petroleum Ether & 1.89 & 1.3715 \\
\hline $\mathrm{D} 9 / 25$ & Heptane & 1.9113 & 1.3878 \\
\hline $\mathrm{D} 9 / 26$ & Heptane & 1.9113 & 1.3878 \\
\hline $\mathrm{D} 9 / 27$ & Heptane & 1.9113 & 1.3878 \\
\hline D9/29 & Water & 78.355 & 1.3328 \\
\hline $\mathrm{D} 9 / 30$ & Water & 78.355 & 1.3328 \\
\hline $\mathrm{D} 9 / 31$ & Water & 78.355 & 1.3328 \\
\hline $\mathrm{D} 9 / 32$ & $\mathrm{NaOH}(\mathrm{aq})$ & 78.355 & 1.3328 \\
\hline D9/33 & Ethanol & 24.852 & 1.3611 \\
\hline $\mathrm{D} 9 / 34$ & Ethanol & 24.852 & 1.3611 \\
\hline D9/35 & Ethanol & 24.852 & 1.3611 \\
\hline $\mathrm{D} 9 / 36$ & Ethanol & 24.852 & 1.3611 \\
\hline $\mathrm{D} 9 / 37$ & Ethanol & 24.852 & 1.3611 \\
\hline D9/39 & Ethanol & 24.852 & 1.3611 \\
\hline D9/41 & Cyclohexane & 2.0165 & 1.4266 \\
\hline $\mathrm{D} 9 / 42$ & Cyclohexane & 2.0165 & 1.4266 \\
\hline D9/45 & Water & 78.355 & 1.3328 \\
\hline D9/47 & Methanol & 32.613 & 1.3288 \\
\hline $\mathrm{D} 9 / 49$ & $\mathrm{KOH}(\mathrm{aq})$ & 78.355 & 1.3328 \\
\hline $\mathrm{D} 9 / 50$ & Methanol & 32.613 & 1.3288 \\
\hline $\mathrm{D} 10 / 40$ & Methanol & 32.613 & 1.3288 \\
\hline $\mathrm{D} 10 / 41$ & Ethanol & 24.852 & 1.3611 \\
\hline $\mathrm{D} 11 / 9$ & Ethanol & 24.852 & 1.3611 \\
\hline $\mathrm{D} 11 / 10$ & Cyclohexane & 2.0165 & 1.4266 \\
\hline $\mathrm{D} 11 / 13$ & Ethanol & 24.852 & 1.3611 \\
\hline $\mathrm{D} 11 / 14$ & Cyclohexane & 2.0165 & 1.4266 \\
\hline $\mathrm{D} 11 / 15$ & Hexane & 1.8819 & 1.3749 \\
\hline $\mathrm{D} 11 / 19$ & Ethanol & 24.852 & 1.3611 \\
\hline $\mathrm{D} 11 / 20$ & Methanol & 32.613 & 1.3288 \\
\hline $\mathrm{D} 11 / 21$ & Methanol & 32.613 & 1.3288 \\
\hline $\mathrm{D} 11 / 23$ & Methanol & 32.613 & 1.3288 \\
\hline $\mathrm{E} 1 / 6$ & Methanol & 32.613 & 1.3288 \\
\hline $\mathrm{E} 1 / 7$ & $0.1 \mathrm{M} \mathrm{KOH}$ & 78.355 & 1.3328 \\
\hline $\mathrm{E} 1 / 9$ & $0.1 \mathrm{M} \mathrm{KOH}$ & 78.355 & 1.3328 \\
\hline $\mathrm{E} 1 / 10$ & Methanol & 32.613 & 1.3288 \\
\hline E1/11 & Methanol & 32.613 & 1.3288 \\
\hline $\mathrm{E} 1 / 14$ & Methanol & 32.613 & 1.3288 \\
\hline $\mathrm{G} 2 / 1$ & Heptane & 1.9113 & 1.3878 \\
\hline $\mathrm{G} 2 / 2$ & Water & 78.355 & 1.3328 \\
\hline G5/7 & $\mathrm{H} 2 \mathrm{SO} 4$ (aq) & 78.355 & 1.3328 \\
\hline G5/8 & Heptane & 1.9113 & 1.3878 \\
\hline G5/9 & Heptane & 1.9113 & 1.3878 \\
\hline G11/15 & Heptane & 1.9113 & 1.3878 \\
\hline $\mathrm{H} 1 / 13$ & $1 \mathrm{M} \mathrm{NaOH}$ & 78.355 & 1.3328 \\
\hline $\mathrm{H} 1 / 15$ & $0.1 \mathrm{M} \mathrm{HCl}$ & 78.355 & 1.3328 \\
\hline $\mathrm{H} 1 / 16$ & $0.01 \mathrm{M} \mathrm{KOH}$ & 78.355 & 1.3328 \\
\hline $\mathrm{H} 1 / 17$ & Methanol & 32.613 & 1.3288 \\
\hline $\mathrm{H} 1 / 18$ & $0.1 \mathrm{M} \mathrm{HCl}$ & 78.355 & 1.3328 \\
\hline $\mathrm{H} 1 / 19$ & $0.1 \mathrm{M} \mathrm{NaOH}$ & 78.355 & 1.3328 \\
\hline $\mathrm{H} 12 / 2$ & Ethanol & 24.852 & 1.3611 \\
\hline $\mathrm{H} 12 / 5$ & Ethanol & 24.852 & 1.3611 \\
\hline
\end{tabular}


Table S2: A table of $f_{\text {comp }}, f_{\text {exp,g1 }}, f_{\text {exp,g2 }}, f_{\text {exp,g }}, f_{\text {exp,n1 }}, f_{\text {exp,n2 }}, f_{\text {exp,n }}$, total score (out of 20) and category (VL, L, M, H, and $\mathrm{VH})$ for each of the 164 transitions.

\begin{tabular}{|c|c|c|c|c|c|c|c|c|c|c|c|c|}
\hline ID & Band & $f_{\text {comp }}$ & $f_{\text {exp }, g 1}$ & $f_{\text {exp,gz }}$ & $f_{\text {exp }, \mathrm{g}}$ & $f_{\text {exp,g1 } 1 / n}$ & $f_{\text {exp }, 81 \times n}$ & $f_{\text {exp,n1 }}$ & $f_{\mathrm{exp}, \mathrm{n} 2}$ & $f_{\text {exp }, n}$ & Score & Category \\
\hline 000 & 1 & 3.89E-01 & 2.97E-01 & 2.98E-01 & $2.98 \mathrm{E}-01$ & 2.14E-01 & 4.13E-01 & 2.64E-01 & $2.60 \mathrm{E}-01$ & $2.62 \mathrm{E}-01$ & 10 & $\mathrm{~L}$ \\
\hline 001 & 1 & 3.63E-01 & $3.06 \mathrm{E}-01$ & 2.99E-01 & 3.03E-01 & 2.18E-01 & $4.20 \mathrm{E}-01$ & 2.77E-01 & $2.83 \mathrm{E}-01$ & $2.80 \mathrm{E}-01$ & 9 & $\mathrm{~L}$ \\
\hline 002 & 1 & $4.16 \mathrm{E}-01$ & $3.28 \mathrm{E}-01$ & 3.30E-01 & $3.29 \mathrm{E}-01$ & $2.37 \mathrm{E}-01$ & $4.56 \mathrm{E}-01$ & 3.07E-01 & 3.07E-01 & $3.07 \mathrm{E}-01$ & 14 & M \\
\hline 003 & 1 & 5.36E-01 & 4.20E-01 & $4.00 \mathrm{E}-01$ & 4.10E-01 & $2.95 \mathrm{E}-01$ & $5.69 \mathrm{E}-01$ & 3.87E-01 & $3.81 \mathrm{E}-01$ & $3.84 \mathrm{E}-01$ & 9 & $\mathrm{~L}$ \\
\hline 004 & 1 & 8.99E-01 & 7.15E-01 & 7.07E-01 & 7.11E-01 & $5.12 \mathrm{E}-01$ & $9.87 \mathrm{E}-01$ & 6.79E-01 & 6.69E-01 & $6.74 \mathrm{E}-01$ & 13 & $M$ \\
\hline 005 & 1 & $1.10 \mathrm{E}+00$ & 7.65E-01 & $7.04 \mathrm{E}-01$ & $7.35 \mathrm{E}-01$ & $5.29 \mathrm{E}-01$ & $1.02 \mathrm{E}+00$ & 7.06E-01 & $6.96 \mathrm{E}-01$ & $7.01 \mathrm{E}-01$ & 9 & L \\
\hline 006 & 1 & $2.63 \mathrm{E}-01$ & $1.75 \mathrm{E}-01$ & $1.87 \mathrm{E}-01$ & $1.81 \mathrm{E}-01$ & $1.32 \mathrm{E}-01$ & $2.49 \mathrm{E}-01$ & $1.83 \mathrm{E}-01$ & $1.87 \mathrm{E}-01$ & $1.85 \mathrm{E}-01$ & 10 & L \\
\hline 007 & 1 & $7.24 \mathrm{E}-01$ & 4.79E-01 & $5.01 \mathrm{E}-01$ & 4.90E-01 & $3.53 \mathrm{E}-01$ & $6.80 \mathrm{E}-01$ & $5.05 \mathrm{E}-01$ & $5.13 \mathrm{E}-01$ & $5.09 \mathrm{E}-01$ & 11 & L \\
\hline 008 & 1 & $4.32 \mathrm{E}-01$ & 3.60E-01 & $3.43 \mathrm{E}-01$ & $3.51 \mathrm{E}-01$ & $2.58 \mathrm{E}-01$ & $4.78 \mathrm{E}-01$ & $3.25 \mathrm{E}-01$ & $3.25 \mathrm{E}-01$ & $3.25 \mathrm{E}-01$ & 9 & $\mathrm{~L}$ \\
\hline 009 & 1 & $5.07 \mathrm{E}-01$ & 3.95E-01 & $3.99 \mathrm{E}-01$ & $3.97 \mathrm{E}-01$ & $2.92 \mathrm{E}-01$ & $5.41 \mathrm{E}-01$ & $3.60 \mathrm{E}-01$ & 3.61E-01 & $3.60 \mathrm{E}-01$ & 11 & L \\
\hline 010 & 1 & $1.34 \mathrm{E}-01$ & $1.14 \mathrm{E}-01$ & $1.09 \mathrm{E}-01$ & $1.11 \mathrm{E}-01$ & $8.10 \mathrm{E}-02$ & $1.53 \mathrm{E}-01$ & $8.88 \mathrm{E}-02$ & $8.80 \mathrm{E}-02$ & $8.84 \mathrm{E}-02$ & 7 & VL \\
\hline 011 & 2 & 4.37E-01 & 5.10E-01 & $5.14 \mathrm{E}-01$ & $5.12 \mathrm{E}-01$ & $3.72 \mathrm{E}-01$ & $7.04 \mathrm{E}-01$ & 4.80E-01 & $4.80 \mathrm{E}-01$ & $4.80 \mathrm{E}-01$ & 14 & $M$ \\
\hline 012 & 1 & $2.97 \mathrm{E}-02$ & 3.30E-02 & $3.30 \mathrm{E}-02$ & $3.30 \mathrm{E}-02$ & $2.26 \mathrm{E}-02$ & $4.83 \mathrm{E}-02$ & $3.25 \mathrm{E}-02$ & $3.23 \mathrm{E}-02$ & $3.24 \mathrm{E}-02$ & 19 & $\mathrm{H}$ \\
\hline 012 & 2 & $3.35 \mathrm{E}-01$ & 1.99E-01 & $1.84 \mathrm{E}-01$ & $1.92 \mathrm{E}-01$ & $1.31 \mathrm{E}-01$ & $2.80 \mathrm{E}-01$ & 1.43E-01 & $1.36 \mathrm{E}-01$ & $1.40 \mathrm{E}-01$ & 2 & VL \\
\hline 013 & 1 & $3.15 \mathrm{E}-02$ & $2.69 \mathrm{E}-02$ & $2.62 \mathrm{E}-02$ & $2.66 \mathrm{E}-02$ & $1.93 \mathrm{E}-02$ & $3.65 \mathrm{E}-02$ & $2.66 \mathrm{E}-02$ & $2.64 \mathrm{E}-02$ & $2.65 \mathrm{E}-02$ & 18 & $\mathrm{H}$ \\
\hline 013 & 2 & $3.12 \mathrm{E}-01$ & $2.40 \mathrm{E}-01$ & $2.36 \mathrm{E}-01$ & $2.38 \mathrm{E}-01$ & $1.73 \mathrm{E}-01$ & $3.27 \mathrm{E}-01$ & $2.21 \mathrm{E}-01$ & $2.21 \mathrm{E}-01$ & $2.21 \mathrm{E}-01$ & 12 & $M$ \\
\hline 014 & 1 & $3.04 \mathrm{E}-01$ & $1.98 \mathrm{E}-01$ & $2.08 \mathrm{E}-01$ & $2.03 \mathrm{E}-01$ & $1.49 \mathrm{E}-01$ & $2.77 \mathrm{E}-01$ & $2.08 \mathrm{E}-01$ & $2.03 \mathrm{E}-01$ & $2.05 \mathrm{E}-01$ & 11 & L \\
\hline 014 & 2 & $9.29 \mathrm{E}-02$ & $1.12 \mathrm{E}-01$ & $1.03 \mathrm{E}-01$ & $1.08 \mathrm{E}-01$ & $7.90 \mathrm{E}-02$ & $1.46 \mathrm{E}-01$ & $9.74 \mathrm{E}-02$ & $9.08 \mathrm{E}-02$ & $9.41 \mathrm{E}-02$ & 2 & VL \\
\hline 015 & 1 & $3.49 \mathrm{E}-01$ & 2.09E-01 & $2.07 \mathrm{E}-01$ & $2.08 \mathrm{E}-01$ & $1.56 \mathrm{E}-01$ & $2.77 \mathrm{E}-01$ & $2.29 \mathrm{E}-01$ & $2.38 \mathrm{E}-01$ & $2.33 \mathrm{E}-01$ & 8 & $\mathrm{~L}$ \\
\hline 015 & 2 & $1.65 \mathrm{E}-01$ & 5.09E-01 & $4.24 \mathrm{E}-01$ & $4.67 \mathrm{E}-01$ & 3.50E-01 & $6.22 \mathrm{E}-01$ & $3.26 \mathrm{E}-01$ & 3.12E-01 & $3.19 \mathrm{E}-01$ & 2 & VL \\
\hline 016 & 1 & $9.02 \mathrm{E}-02$ & 7.93E-02 & 7.96E-02 & $7.95 \mathrm{E}-02$ & $5.73 \mathrm{E}-02$ & $1.10 \mathrm{E}-01$ & 7.73E-02 & 7.59E-02 & $7.66 \mathrm{E}-02$ & 16 & $M$ \\
\hline 017 & 2 & $2.03 \mathrm{E}-01$ & $1.36 \mathrm{E}-01$ & $1.37 \mathrm{E}-01$ & $1.37 \mathrm{E}-01$ & $9.93 \mathrm{E}-02$ & $1.88 \mathrm{E}-01$ & 1.17E-01 & 1.17E-01 & $1.17 \mathrm{E}-01$ & 11 & L \\
\hline 018 & 2 & $8.52 \mathrm{E}-02$ & $9.68 \mathrm{E}-02$ & 8.07E-02 & $8.88 \mathrm{E}-02$ & $6.46 \mathrm{E}-02$ & $1.22 \mathrm{E}-01$ & $8.46 \mathrm{E}-02$ & $8.42 \mathrm{E}-02$ & $8.44 \mathrm{E}-02$ & 6 & $\mathrm{VL}$ \\
\hline 019 & 2 & $1.14 \mathrm{E}-01$ & $8.11 \mathrm{E}-02$ & $7.06 \mathrm{E}-02$ & $7.59 \mathrm{E}-02$ & $5.52 \mathrm{E}-02$ & $1.04 \mathrm{E}-01$ & $6.04 \mathrm{E}-02$ & $6.05 \mathrm{E}-02$ & $6.05 \mathrm{E}-02$ & 5 & VL \\
\hline 020 & $1+2$ & $1.00 \mathrm{E}+00$ & 5.87E-01 & $6.01 \mathrm{E}-01$ & $5.94 \mathrm{E}-01$ & 4.36E-01 & $8.09 \mathrm{E}-01$ & 5.93E-01 & $5.96 \mathrm{E}-01$ & $5.95 \mathrm{E}-01$ & 18 & $\mathrm{H}$ \\
\hline 021 & $1+2$ & $1.07 E+00$ & 7.05E-01 & $6.58 \mathrm{E}-01$ & $6.82 \mathrm{E}-01$ & $5.01 \mathrm{E}-01$ & $9.28 \mathrm{E}-01$ & $6.80 \mathrm{E}-01$ & $6.79 \mathrm{E}-01$ & $6.80 \mathrm{E}-01$ & 11 & $\mathrm{~L}$ \\
\hline 022 & 1 & $7.92 \mathrm{E}-01$ & 4.67E-01 & $4.66 \mathrm{E}-01$ & $4.67 \mathrm{E}-01$ & $3.43 \mathrm{E}-01$ & $6.35 \mathrm{E}-01$ & 4.59E-01 & 4.60E-01 & $4.59 \mathrm{E}-01$ & 19 & $\mathrm{H}$ \\
\hline 022 & 2 & $6.53 \mathrm{E}-01$ & $6.81 \mathrm{E}-01$ & $6.52 \mathrm{E}-01$ & $6.66 \mathrm{E}-01$ & $4.89 \mathrm{E}-01$ & $9.07 \mathrm{E}-01$ & $6.04 \mathrm{E}-01$ & $5.96 \mathrm{E}-01$ & $6.00 \mathrm{E}-01$ & 6 & VL \\
\hline 023 & 2 & $5.65 \mathrm{E}-02$ & $8.81 \mathrm{E}-02$ & $8.40 \mathrm{E}-02$ & $8.61 \mathrm{E}-02$ & $6.05 \mathrm{E}-02$ & $1.22 \mathrm{E}-01$ & $8.34 \mathrm{E}-02$ & $8.34 \mathrm{E}-02$ & $8.34 \mathrm{E}-02$ & 13 & $M$ \\
\hline 024 & 2 & $2.96 \mathrm{E}-01$ & 3.10E-01 & $3.19 \mathrm{E}-01$ & $3.14 \mathrm{E}-01$ & $2.31 \mathrm{E}-01$ & $4.28 \mathrm{E}-01$ & $3.28 \mathrm{E}-01$ & 3.33E-01 & $3.31 \mathrm{E}-01$ & 12 & $M$ \\
\hline 025 & 2 & 5.87E-01 & $3.78 \mathrm{E}-01$ & 3.87E-01 & $3.82 \mathrm{E}-01$ & $2.69 \mathrm{E}-01$ & $5.44 \mathrm{E}-01$ & $3.23 \mathrm{E}-01$ & $3.26 \mathrm{E}-01$ & $3.24 \mathrm{E}-01$ & 8 & $\mathrm{~L}$ \\
\hline 026 & 2 & $9.52 \mathrm{E}-01$ & 5.77E-01 & $5.84 \mathrm{E}-01$ & $5.80 \mathrm{E}-01$ & $4.22 \mathrm{E}-01$ & $7.98 \mathrm{E}-01$ & 5.71E-01 & 5.77E-01 & $5.74 \mathrm{E}-01$ & 17 & $\mathrm{H}$ \\
\hline 026 & 3 & $2.08 \mathrm{E}-01$ & 2.49E-01 & $2.49 \mathrm{E}-01$ & $2.49 \mathrm{E}-01$ & $1.81 \mathrm{E}-01$ & $3.42 \mathrm{E}-01$ & $2.58 \mathrm{E}-01$ & $2.56 \mathrm{E}-01$ & $2.57 \mathrm{E}-01$ & 16 & $M$ \\
\hline 027 & 1 & $1.26 \mathrm{E}+00$ & 7.24E-01 & 7.10E-01 & 7.17E-01 & $5.38 \mathrm{E}-01$ & $9.55 \mathrm{E}-01$ & $7.31 \mathrm{E}-01$ & 7.14E-01 & $7.22 \mathrm{E}-01$ & 17 & $\mathrm{H}$ \\
\hline 027 & $2+3$ & $2.43 \mathrm{E}-01$ & $5.05 \mathrm{E}-01$ & 4.96E-01 & $5.01 \mathrm{E}-01$ & 3.76E-01 & $6.67 \mathrm{E}-01$ & 4.83E-01 & 4.77E-01 & $4.80 \mathrm{E}-01$ & 14 & $M$ \\
\hline 028 & 1 & $1.03 E+00$ & $5.76 \mathrm{E}-01$ & $5.66 \mathrm{E}-01$ & $5.71 \mathrm{E}-01$ & 4.19E-01 & 7.77E-01 & $5.84 \mathrm{E}-01$ & $5.75 \mathrm{E}-01$ & $5.80 \mathrm{E}-01$ & 17 & $\mathrm{H}$ \\
\hline 029 & 1 & $3.57 \mathrm{E}-02$ & $1.36 \mathrm{E}-02$ & $1.39 \mathrm{E}-02$ & $1.38 \mathrm{E}-02$ & $1.02 \mathrm{E}-02$ & $1.85 \mathrm{E}-02$ & 1.17E-02 & $1.15 \mathrm{E}-02$ & $1.16 \mathrm{E}-02$ & 7 & VL \\
\hline 029 & 2 & $8.81 \mathrm{E}-01$ & $5.98 \mathrm{E}-01$ & $6.01 \mathrm{E}-01$ & $6.00 \mathrm{E}-01$ & $4.46 \mathrm{E}-01$ & $8.06 \mathrm{E}-01$ & 5.69E-01 & $5.74 \mathrm{E}-01$ & $5.71 \mathrm{E}-01$ & 16 & $M$ \\
\hline 030 & 1 & $5.08 \mathrm{E}-01$ & $2.90 \mathrm{E}-01$ & $2.76 \mathrm{E}-01$ & $2.83 \mathrm{E}-01$ & $1.99 \mathrm{E}-01$ & $4.02 \mathrm{E}-01$ & $2.80 \mathrm{E}-01$ & $2.77 \mathrm{E}-01$ & $2.79 \mathrm{E}-01$ & 14 & $M$ \\
\hline 030 & 2 & $4.02 \mathrm{E}-01$ & $2.48 \mathrm{E}-01$ & $3.02 \mathrm{E}-01$ & $2.75 \mathrm{E}-01$ & $1.93 \mathrm{E}-01$ & $3.91 \mathrm{E}-01$ & $2.53 \mathrm{E}-01$ & $2.57 \mathrm{E}-01$ & $2.55 \mathrm{E}-01$ & 3 & VL \\
\hline 031 & 2 & 7.99E-01 & 4.07E-01 & $4.11 \mathrm{E}-01$ & $4.09 \mathrm{E}-01$ & $2.88 \mathrm{E}-01$ & $5.82 \mathrm{E}-01$ & $4.28 \mathrm{E}-01$ & $4.28 \mathrm{E}-01$ & $4.28 \mathrm{E}-01$ & 16 & $M$ \\
\hline 032 & 1 & $4.78 \mathrm{E}-01$ & 3.36E-01 & 3.36E-01 & 3.36E-01 & $2.47 \mathrm{E}-01$ & $4.57 \mathrm{E}-01$ & 3.13E-01 & 3.11E-01 & $3.12 \mathrm{E}-01$ & 13 & $M$ \\
\hline 033 & 1 & $1.03 E+00$ & $7.42 \mathrm{E}-01$ & $7.46 \mathrm{E}-01$ & $7.44 \mathrm{E}-01$ & $5.47 \mathrm{E}-01$ & $1.01 \mathrm{E}+00$ & $7.42 \mathrm{E}-01$ & $7.46 \mathrm{E}-01$ & $7.44 \mathrm{E}-01$ & 20 & $\mathrm{VH}$ \\
\hline 033 & 2 & $5.26 \mathrm{E}-02$ & $2.94 \mathrm{E}-02$ & $2.91 \mathrm{E}-02$ & $2.93 \mathrm{E}-02$ & $2.15 \mathrm{E}-02$ & $3.98 \mathrm{E}-02$ & $2.75 \mathrm{E}-02$ & $2.75 \mathrm{E}-02$ & $2.75 \mathrm{E}-02$ & 14 & $M$ \\
\hline 034 & $1+2+3$ & $5.18 \mathrm{E}-01$ & 3.54E-01 & $3.52 \mathrm{E}-01$ & 3.53E-01 & $2.57 \mathrm{E}-01$ & $4.85 \mathrm{E}-01$ & $3.54 \mathrm{E}-01$ & $3.52 \mathrm{E}-01$ & $3.53 \mathrm{E}-01$ & 20 & $\mathrm{VH}$ \\
\hline 035 & 1 & $6.57 \mathrm{E}-01$ & $2.48 \mathrm{E}-01$ & $2.57 \mathrm{E}-01$ & $2.53 \mathrm{E}-01$ & $1.86 \mathrm{E}-01$ & $3.44 \mathrm{E}-01$ & $2.99 \mathrm{E}-01$ & 3.07E-01 & $3.03 \mathrm{E}-01$ & 6 & VL \\
\hline 036 & 1 & $7.27 \mathrm{E}-01$ & 5.00E-01 & $4.89 \mathrm{E}-01$ & $4.95 \mathrm{E}-01$ & $3.63 \mathrm{E}-01$ & $6.73 \mathrm{E}-01$ & $5.05 \mathrm{E}-01$ & 4.91E-01 & $4.98 \mathrm{E}-01$ & 16 & $M$ \\
\hline 036 & 2 & 3.56E-01 & 3.19E-01 & $2.99 \mathrm{E}-01$ & $3.09 \mathrm{E}-01$ & $2.27 \mathrm{E}-01$ & $4.20 \mathrm{E}-01$ & 3.37E-01 & $3.26 \mathrm{E}-01$ & $3.32 \mathrm{E}-01$ & 4 & VL \\
\hline 037 & 1 & $6.39 \mathrm{E}-01$ & 5.37E-01 & $5.54 \mathrm{E}-01$ & $5.46 \mathrm{E}-01$ & $4.01 \mathrm{E}-01$ & $7.43 \mathrm{E}-01$ & $5.44 \mathrm{E}-01$ & 5.54E-01 & $5.49 \mathrm{E}-01$ & 16 & $M$ \\
\hline 038 & $1+2$ & $8.61 \mathrm{E}-01$ & $5.06 \mathrm{E}-01$ & 4.87E-01 & 4.97E-01 & $3.65 \mathrm{E}-01$ & $6.76 \mathrm{E}-01$ & $5.34 \mathrm{E}-01$ & 5.31E-01 & $5.32 \mathrm{E}-01$ & 10 & L \\
\hline 039 & 1 & $7.90 \mathrm{E}-01$ & $6.46 \mathrm{E}-01$ & $6.61 \mathrm{E}-01$ & $6.54 \mathrm{E}-01$ & $4.80 \mathrm{E}-01$ & $8.90 \mathrm{E}-01$ & $6.50 \mathrm{E}-01$ & 6.59E-01 & $6.55 \mathrm{E}-01$ & 17 & $\mathrm{H}$ \\
\hline
\end{tabular}




\begin{tabular}{|c|c|c|c|c|c|c|c|c|c|c|c|c|}
\hline 40 & 1 & 8.09E-01 & $3.91 \mathrm{E}-01$ & 4.10E-01 & 4.00E-01 & $3.01 \mathrm{E}-01$ & $5.32 \mathrm{E}-01$ & $4.22 \mathrm{E}-01$ & $4.26 \mathrm{E}-01$ & 4.24E-01 & 10 & $\mathrm{~L}$ \\
\hline 040 & 2 & 6.17E-01 & 5.55E-01 & $5.22 \mathrm{E}-01$ & 5.38E-01 & 4.05E-01 & 7.15E-01 & 5.15E-01 & 5.09E-01 & 5.12E-01 & 9 & $\mathrm{~L}$ \\
\hline 041 & $2+3$ & $1.50 \mathrm{E}+00$ & $1.08 \mathrm{E}+00$ & $1.05 E+00$ & $1.06 \mathrm{E}+00$ & $7.67 \mathrm{E}-01$ & $1.48 \mathrm{E}+00$ & $9.85 \mathrm{E}-01$ & $9.53 \mathrm{E}-01$ & $9.69 \mathrm{E}-01$ & 7 & VL \\
\hline 042 & 2 & $2.21 \mathrm{E}-02$ & $1.12 \mathrm{E}-01$ & 1.16E-01 & $1.14 \mathrm{E}-01$ & $8.22 \mathrm{E}-02$ & $1.58 \mathrm{E}-01$ & $1.14 \mathrm{E}-01$ & $1.12 \mathrm{E}-01$ & $1.13 \mathrm{E}-01$ & 14 & $M$ \\
\hline 042 & 3 & $1.35 \mathrm{E}+00$ & $9.37 \mathrm{E}-01$ & $9.00 \mathrm{E}-01$ & $9.18 \mathrm{E}-01$ & $6.62 \mathrm{E}-01$ & $1.27 \mathrm{E}+00$ & 8.33E-01 & $8.35 \mathrm{E}-01$ & $8.34 \mathrm{E}-01$ & 8 & $\mathrm{~L}$ \\
\hline 043 & 2 & 7.44E-02 & $1.35 \mathrm{E}-01$ & 1.33E-01 & $1.34 \mathrm{E}-01$ & $9.67 \mathrm{E}-02$ & $1.86 \mathrm{E}-01$ & $1.27 \mathrm{E}-01$ & $1.24 \mathrm{E}-01$ & $1.26 \mathrm{E}-01$ & 10 & L \\
\hline 043 & 3 & $1.32 \mathrm{E}+00$ & $9.71 \mathrm{E}-01$ & $9.50 \mathrm{E}-01$ & $9.61 \mathrm{E}-01$ & $6.92 \mathrm{E}-01$ & $1.33 \mathrm{E}+00$ & $8.81 \mathrm{E}-01$ & 8.69E-01 & 8.75E-01 & 9 & L \\
\hline 044 & 1 & 8.67E-02 & 3.35E-02 & $3.37 \mathrm{E}-02$ & 3.36E-02 & $2.46 \mathrm{E}-02$ & 4.59E-02 & $3.34 \mathrm{E}-02$ & $3.34 \mathrm{E}-02$ & 3.34E-02 & 18 & $\mathrm{H}$ \\
\hline 044 & $2+3$ & $1.31 \mathrm{E}+00$ & $1.06 \mathrm{E}+00$ & $1.05 E+00$ & $1.06 \mathrm{E}+00$ & 7.74E-01 & $1.44 \mathrm{E}+00$ & $9.96 \mathrm{E}-01$ & $9.92 \mathrm{E}-01$ & $9.94 \mathrm{E}-01$ & 14 & $M$ \\
\hline 045 & 1 & 4.77E-02 & $1.86 \mathrm{E}-02$ & $1.79 \mathrm{E}-02$ & $1.83 \mathrm{E}-02$ & $1.34 \mathrm{E}-02$ & $2.49 \mathrm{E}-02$ & $1.87 \mathrm{E}-02$ & $1.78 \mathrm{E}-02$ & $1.83 \mathrm{E}-02$ & 12 & $M$ \\
\hline 045 & $2+3$ & $1.26 \mathrm{E}+00$ & $1.03 \mathrm{E}+00$ & $1.01 \mathrm{E}+00$ & $1.02 \mathrm{E}+00$ & 7.47E-01 & $1.39 \mathrm{E}+00$ & $9.67 \mathrm{E}-01$ & $9.58 \mathrm{E}-01$ & $9.63 \mathrm{E}-01$ & 13 & $M$ \\
\hline 046 & 1 & 4.50E-02 & 1.96E-02 & $1.94 \mathrm{E}-02$ & 1.95E-02 & 1.46E-02 & 2.60E-02 & $1.97 \mathrm{E}-02$ & $1.98 \mathrm{E}-02$ & 1.98E-02 & 18 & $\mathrm{H}$ \\
\hline 046 & 2 & $5.66 \mathrm{E}-02$ & $1.46 \mathrm{E}-01$ & $1.34 \mathrm{E}-01$ & $1.40 \mathrm{E}-01$ & $1.05 \mathrm{E}-01$ & $1.86 \mathrm{E}-01$ & $1.02 \mathrm{E}-01$ & $1.01 \mathrm{E}-01$ & $1.01 \mathrm{E}-01$ & 5 & VL \\
\hline 047 & 1 & $8.52 \mathrm{E}-02$ & $3.85 \mathrm{E}-02$ & $3.91 \mathrm{E}-02$ & $3.88 \mathrm{E}-02$ & $2.91 \mathrm{E}-02$ & $5.17 \mathrm{E}-02$ & $3.87 \mathrm{E}-02$ & $3.91 \mathrm{E}-02$ & $3.89 \mathrm{E}-02$ & 18 & $\mathrm{H}$ \\
\hline 047 & 2 & 3.96E-01 & 2.01E-01 & $1.91 \mathrm{E}-01$ & 1.96E-01 & 1.47E-01 & 2.61E-01 & $1.86 \mathrm{E}-01$ & $1.86 \mathrm{E}-01$ & 1.86E-01 & 11 & L \\
\hline 048 & 1 & 5.05E-02 & 3.13E-02 & 3.39E-02 & 3.26E-02 & $2.35 \mathrm{E}-02$ & 4.52E-02 & 3.33E-02 & $3.35 \mathrm{E}-02$ & 3.34E-02 & 10 & L \\
\hline 048 & 2 & 4.69E-01 & 2.95E-01 & $2.87 \mathrm{E}-01$ & 2.91E-01 & 2.10E-01 & 4.04E-01 & $2.85 \mathrm{E}-01$ & $2.82 \mathrm{E}-01$ & 2.83E-01 & 16 & $M$ \\
\hline 048 & 3 & $7.59 \mathrm{E}-01$ & 4.20E-01 & 4.62E-01 & 4.41E-01 & $3.18 \mathrm{E}-01$ & $6.12 \mathrm{E}-01$ & $4.72 \mathrm{E}-01$ & 4.76E-01 & 4.74E-01 & 7 & VL \\
\hline 049 & $1+2$ & $3.02 \mathrm{E}-01$ & $2.45 \mathrm{E}-01$ & $2.43 \mathrm{E}-01$ & $2.44 \mathrm{E}-01$ & $1.79 \mathrm{E}-01$ & 3.33E-01 & $2.44 \mathrm{E}-01$ & $2.43 \mathrm{E}-01$ & $2.44 \mathrm{E}-01$ & 20 & $\mathrm{VH}$ \\
\hline 050 & 2 & $6.43 \mathrm{E}-02$ & $1.14 \mathrm{E}-01$ & $1.14 \mathrm{E}-01$ & $1.14 \mathrm{E}-01$ & $8.20 \mathrm{E}-02$ & $1.58 \mathrm{E}-01$ & $1.10 \mathrm{E}-01$ & $1.08 \mathrm{E}-01$ & $1.09 \mathrm{E}-01$ & 15 & $M$ \\
\hline 050 & 3 & $1.30 \mathrm{E}+00$ & $8.30 \mathrm{E}-01$ & 7.90E-01 & $8.10 \mathrm{E}-01$ & $5.84 \mathrm{E}-01$ & $1.12 \mathrm{E}+00$ & $7.68 \mathrm{E}-01$ & 7.61E-01 & 7.64E-01 & 10 & L \\
\hline 051 & 2 & 1.66E-01 & 1.66E-01 & $1.56 \mathrm{E}-01$ & $1.61 \mathrm{E}-01$ & 1.16E-01 & $2.24 \mathrm{E}-01$ & $1.50 \mathrm{E}-01$ & $1.52 \mathrm{E}-01$ & $1.51 \mathrm{E}-01$ & 7 & VL \\
\hline 051 & 3 & $1.18 \mathrm{E}+00$ & $7.45 \mathrm{E}-01$ & 8.00E-01 & 7.73E-01 & 5.57E-01 & $1.07 E+00$ & $7.72 \mathrm{E}-01$ & 7.63E-01 & 7.68E-01 & 8 & L \\
\hline 052 & 1 & $2.22 \mathrm{E}-02$ & $1.23 \mathrm{E}-02$ & 1.13E-02 & $1.18 \mathrm{E}-02$ & $8.50 \mathrm{E}-03$ & $1.64 \mathrm{E}-02$ & $1.13 \mathrm{E}-02$ & $1.10 \mathrm{E}-02$ & $1.12 \mathrm{E}-02$ & 5 & $\mathrm{VL}$ \\
\hline 052 & 2 & 1.83E-01 & $1.58 \mathrm{E}-01$ & $1.52 \mathrm{E}-01$ & 1.55E-01 & 1.12E-01 & $2.15 \mathrm{E}-01$ & $1.34 \mathrm{E}-01$ & $1.27 \mathrm{E}-01$ & 1.31E-01 & 3 & VL \\
\hline 052 & 3 & 7.65E-01 & 7.21E-01 & $6.76 \mathrm{E}-01$ & 6.99E-01 & 5.03E-01 & $9.69 \mathrm{E}-01$ & $6.46 \mathrm{E}-01$ & 6.33E-01 & 6.39E-01 & 4 & VL \\
\hline 053 & 1 & $6.40 \mathrm{E}-02$ & $6.78 \mathrm{E}-02$ & 7.01E-02 & $6.90 \mathrm{E}-02$ & $5.17 \mathrm{E}-02$ & $9.19 \mathrm{E}-02$ & $6.99 \mathrm{E}-02$ & $7.21 \mathrm{E}-02$ & $7.10 \mathrm{E}-02$ & 12 & $M$ \\
\hline 053 & 2 & 2.79E-01 & 1.66E-01 & 1.69E-01 & $1.68 \mathrm{E}-01$ & $1.26 \mathrm{E}-01$ & $2.23 \mathrm{E}-01$ & $1.64 \mathrm{E}-01$ & $1.68 \mathrm{E}-01$ & 1.66E-01 & 17 & $\mathrm{H}$ \\
\hline 054 & 1 & 3.69E-02 & 3.94E-02 & 4.10E-02 & 4.02E-02 & $3.02 \mathrm{E}-02$ & $5.36 \mathrm{E}-02$ & $3.76 \mathrm{E}-02$ & 3.69E-02 & 3.73E-02 & 9 & L \\
\hline 054 & 2 & $2.18 \mathrm{E}-01$ & $1.52 \mathrm{E}-01$ & $1.50 \mathrm{E}-01$ & 1.51E-01 & 1.13E-01 & $2.01 \mathrm{E}-01$ & $1.42 \mathrm{E}-01$ & $1.45 \mathrm{E}-01$ & $1.44 \mathrm{E}-01$ & 14 & $M$ \\
\hline 054 & 3 & $9.35 \mathrm{E}-02$ & $9.33 \mathrm{E}-02$ & $9.62 \mathrm{E}-02$ & $9.48 \mathrm{E}-02$ & $7.11 \mathrm{E}-02$ & $1.26 \mathrm{E}-01$ & $1.26 \mathrm{E}-01$ & $1.25 \mathrm{E}-01$ & $1.26 \mathrm{E}-01$ & 7 & VL \\
\hline 054 & 4 & 3.10E-01 & 2.91E-01 & $2.65 \mathrm{E}-01$ & 2.78E-01 & $2.08 \mathrm{E}-01$ & 3.70E-01 & $2.65 \mathrm{E}-01$ & $2.66 \mathrm{E}-01$ & 2.66E-01 & 8 & L \\
\hline 055 & 1 & 3.83E-01 & $2.81 \mathrm{E}-01$ & $2.78 \mathrm{E}-01$ & 2.79E-01 & 2.10E-01 & $3.72 \mathrm{E}-01$ & $2.82 \mathrm{E}-01$ & $2.82 \mathrm{E}-01$ & $2.82 \mathrm{E}-01$ & 19 & $\mathrm{H}$ \\
\hline 055 & 2 & 4.72E-02 & $1.68 \mathrm{E}-01$ & $1.76 \mathrm{E}-01$ & $1.72 \mathrm{E}-01$ & 1.29E-01 & 2.29E-01 & $1.50 \mathrm{E}-01$ & $1.48 \mathrm{E}-01$ & 1.49E-01 & 6 & VL \\
\hline 056 & 1 & $5.88 \mathrm{E}-01$ & $3.78 \mathrm{E}-01$ & $3.80 \mathrm{E}-01$ & 3.79E-01 & $2.84 \mathrm{E}-01$ & $5.05 \mathrm{E}-01$ & $3.84 \mathrm{E}-01$ & $3.85 \mathrm{E}-01$ & $3.84 \mathrm{E}-01$ & 19 & H \\
\hline 057 & 1 & $1.01 \mathrm{E}-01$ & $6.74 \mathrm{E}-02$ & $6.74 \mathrm{E}-02$ & $6.74 \mathrm{E}-02$ & 4.95E-02 & $9.18 \mathrm{E}-02$ & $6.75 \mathrm{E}-02$ & $6.77 \mathrm{E}-02$ & $6.76 \mathrm{E}-02$ & 20 & $\mathrm{VH}$ \\
\hline 057 & 2 & $2.56 \mathrm{E}-01$ & 1.40E-01 & $1.40 \mathrm{E}-01$ & $1.40 \mathrm{E}-01$ & $1.03 \mathrm{E}-01$ & $1.91 \mathrm{E}-01$ & $1.42 \mathrm{E}-01$ & $1.42 \mathrm{E}-01$ & $1.42 \mathrm{E}-01$ & 19 & $\mathrm{H}$ \\
\hline 058 & 1 & $5.58 \mathrm{E}-02$ & $7.08 \mathrm{E}-02$ & $6.86 \mathrm{E}-02$ & 6.97E-02 & $5.12 \mathrm{E}-02$ & $9.49 \mathrm{E}-02$ & $7.06 \mathrm{E}-02$ & $6.97 \mathrm{E}-02$ & $7.02 \mathrm{E}-02$ & 16 & $M$ \\
\hline 058 & 2 & 2.30E-01 & $1.44 \mathrm{E}-01$ & $1.45 \mathrm{E}-01$ & $1.45 \mathrm{E}-01$ & 1.06E-01 & 1.97E-01 & $1.43 \mathrm{E}-01$ & $1.42 \mathrm{E}-01$ & $1.42 \mathrm{E}-01$ & 19 & $\mathrm{H}$ \\
\hline 059 & 1 & 8.07E-02 & $6.79 \mathrm{E}-02$ & $6.76 \mathrm{E}-02$ & $6.78 \mathrm{E}-02$ & 4.98E-02 & $9.22 \mathrm{E}-02$ & $6.83 \mathrm{E}-02$ & $6.80 \mathrm{E}-02$ & $6.82 \mathrm{E}-02$ & 20 & $\mathrm{VH}$ \\
\hline 059 & 2 & 2.79E-01 & 1.56E-01 & $1.56 \mathrm{E}-01$ & 1.56E-01 & 1.15E-01 & 2.13E-01 & $1.60 \mathrm{E}-01$ & $1.59 \mathrm{E}-01$ & 1.60E-01 & 18 & $\mathrm{H}$ \\
\hline 060 & 1 & $1.28 \mathrm{E}-01$ & $7.88 \mathrm{E}-02$ & 7.90E-02 & $7.89 \mathrm{E}-02$ & $5.80 \mathrm{E}-02$ & $1.07 \mathrm{E}-01$ & $7.99 \mathrm{E}-02$ & $8.01 \mathrm{E}-02$ & $8.00 \mathrm{E}-02$ & 19 & $\mathrm{H}$ \\
\hline 060 & 2 & $2.43 \mathrm{E}-01$ & $1.74 \mathrm{E}-01$ & $1.76 \mathrm{E}-01$ & 1.75E-01 & 1.29E-01 & $2.38 \mathrm{E}-01$ & $1.75 \mathrm{E}-01$ & $1.75 \mathrm{E}-01$ & 1.75E-01 & 19 & $\mathrm{H}$ \\
\hline 061 & 1 & 1.16E-01 & $9.24 \mathrm{E}-02$ & $9.21 \mathrm{E}-02$ & $9.23 \mathrm{E}-02$ & $6.78 \mathrm{E}-02$ & $1.26 \mathrm{E}-01$ & $9.23 \mathrm{E}-02$ & 9.19E-02 & $9.21 \mathrm{E}-02$ & 20 & $\mathrm{VH}$ \\
\hline 061 & 2 & $6.01 \mathrm{E}-02$ & $6.43 \mathrm{E}-02$ & 6.13E-02 & $6.28 \mathrm{E}-02$ & $4.61 \mathrm{E}-02$ & $8.55 \mathrm{E}-02$ & $6.72 \mathrm{E}-02$ & $6.52 \mathrm{E}-02$ & $6.62 \mathrm{E}-02$ & 8 & L \\
\hline 061 & 3 & $3.86 \mathrm{E}-01$ & $3.92 \mathrm{E}-01$ & 4.29E-01 & 4.10E-01 & $3.01 \mathrm{E}-01$ & 5.59E-01 & $4.28 \mathrm{E}-01$ & $4.28 \mathrm{E}-01$ & $4.28 \mathrm{E}-01$ & 10 & L \\
\hline 062 & 1 & 4.49E-01 & 3.74E-01 & 3.76E-01 & 3.75E-01 & $2.75 \mathrm{E}-01$ & 5.10E-01 & 3.75E-01 & $3.78 \mathrm{E}-01$ & 3.76E-01 & 20 & $\mathrm{VH}$ \\
\hline 062 & 2 & $2.27 \mathrm{E}-01$ & $2.23 \mathrm{E}-01$ & $2.14 \mathrm{E}-01$ & $2.18 \mathrm{E}-01$ & $1.60 \mathrm{E}-01$ & $2.97 \mathrm{E}-01$ & $2.04 \mathrm{E}-01$ & $2.07 \mathrm{E}-01$ & $2.06 \mathrm{E}-01$ & 11 & L \\
\hline 063 & 1 & $6.79 \mathrm{E}-01$ & 5.06E-01 & 4.95E-01 & $5.01 \mathrm{E}-01$ & $3.51 \mathrm{E}-01$ & $7.14 \mathrm{E}-01$ & $5.06 \mathrm{E}-01$ & 4.99E-01 & $5.03 \mathrm{E}-01$ & 17 & $\mathrm{H}$ \\
\hline 063 & 2 & $1.55 \mathrm{E}-01$ & $1.63 \mathrm{E}-01$ & $1.57 \mathrm{E}-01$ & 1.60E-01 & $1.12 \mathrm{E}-01$ & $2.28 \mathrm{E}-01$ & 1.67E-01 & $1.65 \mathrm{E}-01$ & 1.66E-01 & 13 & $M$ \\
\hline 064 & 1 & 4.51E-02 & $2.50 \mathrm{E}-02$ & $2.82 \mathrm{E}-02$ & 2.66E-02 & 1.87E-02 & $3.79 \mathrm{E}-02$ & 2.60E-02 & $2.69 \mathrm{E}-02$ & 2.65E-02 & 6 & VL \\
\hline 064 & $2+3$ & 5.99E-01 & 4.59E-01 & 4.44E-01 & 4.51E-01 & 3.16E-01 & $6.44 \mathrm{E}-01$ & 4.33E-01 & 4.37E-01 & 4.35E-01 & 13 & $M$ \\
\hline 065 & 1 & $6.00 \mathrm{E}-04$ & $1.99 \mathrm{E}-02$ & 1.96E-02 & $1.98 \mathrm{E}-02$ & $1.48 \mathrm{E}-02$ & $2.63 \mathrm{E}-02$ & $1.86 \mathrm{E}-02$ & $1.81 \mathrm{E}-02$ & $1.84 \mathrm{E}-02$ & 10 & L \\
\hline 065 & $2+3$ & $1.63 E+00$ & $1.21 \mathrm{E}+00$ & $1.24 \mathrm{E}+00$ & $1.22 \mathrm{E}+00$ & 9.17E-01 & $1.63 E+00$ & $1.04 \mathrm{E}+00$ & $1.02 \mathrm{E}+00$ & $1.03 E+00$ & 8 & L \\
\hline 066 & 1 & $5.18 \mathrm{E}-01$ & $3.72 \mathrm{E}-01$ & $3.72 \mathrm{E}-01$ & $3.72 \mathrm{E}-01$ & $2.80 \mathrm{E}-01$ & 4.94E-01 & $3.75 \mathrm{E}-01$ & $3.76 \mathrm{E}-01$ & $3.76 \mathrm{E}-01$ & 20 & $\mathrm{VH}$ \\
\hline
\end{tabular}




\begin{tabular}{|c|c|c|c|c|c|c|c|c|c|c|c|c|}
\hline 066 & 2 & 1.10E-01 & $2.33 \mathrm{E}-01$ & $2.38 \mathrm{E}-01$ & $2.35 \mathrm{E}-01$ & 1.77E-01 & 3.13E-01 & 2.09E-01 & 2.09E-01 & 2.09E-01 & 9 & L \\
\hline 067 & 1 & $1.13 \mathrm{E}-01$ & $4.27 \mathrm{E}-02$ & $3.88 \mathrm{E}-02$ & $4.08 \mathrm{E}-02$ & $3.06 \mathrm{E}-02$ & $5.43 \mathrm{E}-02$ & 4.20E-02 & $4.12 \mathrm{E}-02$ & $4.16 \mathrm{E}-02$ & 10 & L \\
\hline 067 & 2 & $2.72 \mathrm{E}-01$ & $1.38 \mathrm{E}-01$ & $1.33 \mathrm{E}-01$ & $1.36 \mathrm{E}-01$ & $1.02 \mathrm{E}-01$ & $1.81 \mathrm{E}-01$ & $1.33 \mathrm{E}-01$ & $1.35 \mathrm{E}-01$ & $1.34 \mathrm{E}-01$ & 14 & $M$ \\
\hline 067 & 3 & $7.38 \mathrm{E}-01$ & $5.92 \mathrm{E}-01$ & $5.47 \mathrm{E}-01$ & $5.69 \mathrm{E}-01$ & 4.27E-01 & $7.59 \mathrm{E}-01$ & $4.85 \mathrm{E}-01$ & 4.76E-01 & $4.80 \mathrm{E}-01$ & 3 & VL \\
\hline 068 & 1 & 1.15E-01 & $9.50 \mathrm{E}-02$ & $9.38 \mathrm{E}-02$ & $9.44 \mathrm{E}-02$ & 7.11E-02 & $1.25 \mathrm{E}-01$ & $9.24 \mathrm{E}-02$ & $9.28 \mathrm{E}-02$ & $9.26 \mathrm{E}-02$ & 18 & $\mathrm{H}$ \\
\hline 068 & 2 & $2.23 \mathrm{E}-01$ & $8.17 \mathrm{E}-02$ & $8.63 \mathrm{E}-02$ & $8.40 \mathrm{E}-02$ & $6.32 \mathrm{E}-02$ & $1.12 \mathrm{E}-01$ & $6.80 \mathrm{E}-02$ & $6.86 \mathrm{E}-02$ & $6.83 \mathrm{E}-02$ & 6 & $\mathrm{VL}$ \\
\hline 068 & 3 & 5.98E-01 & 4.15E-01 & 4.12E-01 & 4.14E-01 & $3.11 \mathrm{E}-01$ & $5.49 \mathrm{E}-01$ & 4.36E-01 & 4.36E-01 & 4.36E-01 & 14 & $M$ \\
\hline 069 & 1 & 8.64E-01 & 5.77E-01 & $5.82 \mathrm{E}-01$ & 5.79E-01 & $4.36 \mathrm{E}-01$ & 7.70E-01 & 5.77E-01 & 5.81E-01 & 5.79E-01 & 20 & $\mathrm{VH}$ \\
\hline 070 & 1 & 8.17E-01 & $5.78 \mathrm{E}-01$ & $5.79 \mathrm{E}-01$ & 5.79E-01 & $4.25 \mathrm{E}-01$ & $7.88 \mathrm{E}-01$ & 5.79E-01 & 5.79E-01 & 5.79E-01 & 20 & $\mathrm{VH}$ \\
\hline 070 & 2 & $1.63 \mathrm{E}-01$ & $1.67 \mathrm{E}-01$ & $1.81 \mathrm{E}-01$ & $1.74 \mathrm{E}-01$ & $1.28 \mathrm{E}-01$ & $2.37 \mathrm{E}-01$ & $1.74 \mathrm{E}-01$ & 1.77E-01 & $1.76 \mathrm{E}-01$ & 10 & L \\
\hline 071 & 2 & 5.34E-01 & $4.12 \mathrm{E}-01$ & 4.19E-01 & 4.16E-01 & $3.05 E-01$ & $5.66 \mathrm{E}-01$ & 4.07E-01 & 3.99E-01 & 4.03E-01 & 15 & $M$ \\
\hline 072 & 2 & 6.01E-01 & $4.29 \mathrm{E}-01$ & 4.14E-01 & 4.21E-01 & $2.95 \mathrm{E}-01$ & $6.01 \mathrm{E}-01$ & 4.37E-01 & 4.35E-01 & 4.36E-01 & 14 & $M$ \\
\hline 073 & 1 & 4.56E-01 & $4.12 \mathrm{E}-01$ & 4.11E-01 & 4.11E-01 & $3.02 \mathrm{E}-01$ & $5.60 \mathrm{E}-01$ & 4.04E-01 & $4.02 \mathrm{E}-01$ & 4.03E-01 & 18 & $\mathrm{H}$ \\
\hline 073 & 2 & 4.43E-01 & $2.88 \mathrm{E}-01$ & 2.71E-01 & $2.80 \mathrm{E}-01$ & $2.05 \mathrm{E}-01$ & $3.81 \mathrm{E}-01$ & 2.97E-01 & 2.95E-01 & 2.96E-01 & 9 & L \\
\hline 074 & 1 & 5.11E-01 & 4.54E-01 & $4.54 \mathrm{E}-01$ & 4.54E-01 & $3.18 \mathrm{E}-01$ & $6.47 \mathrm{E}-01$ & $4.58 \mathrm{E}-01$ & 4.49E-01 & 4.53E-01 & 19 & $\mathrm{H}$ \\
\hline 074 & 2 & 5.54E-01 & $3.83 \mathrm{E}-01$ & $3.73 \mathrm{E}-01$ & 3.78E-01 & $2.65 \mathrm{E}-01$ & 5.39E-01 & 3.89E-01 & 3.83E-01 & $3.86 \mathrm{E}-01$ & 15 & $M$ \\
\hline 075 & $2+3$ & $5.85 \mathrm{E}-01$ & $5.01 \mathrm{E}-01$ & $5.03 \mathrm{E}-01$ & $5.02 \mathrm{E}-01$ & $3.65 \mathrm{E}-01$ & $6.90 \mathrm{E}-01$ & 4.90E-01 & 4.89E-01 & $4.90 \mathrm{E}-01$ & 18 & $\mathrm{H}$ \\
\hline 076 & 1 & $6.72 \mathrm{E}-01$ & $4.56 \mathrm{E}-01$ & 4.69E-01 & 4.63E-01 & $3.40 \mathrm{E}-01$ & $6.30 \mathrm{E}-01$ & 4.86E-01 & 4.89E-01 & 4.88E-01 & 13 & $M$ \\
\hline 077 & 1 & 2.10E-01 & $1.48 \mathrm{E}-01$ & $1.44 \mathrm{E}-01$ & $1.46 \mathrm{E}-01$ & $1.10 \mathrm{E}-01$ & $1.94 \mathrm{E}-01$ & $1.45 \mathrm{E}-01$ & $1.44 \mathrm{E}-01$ & $1.44 \mathrm{E}-01$ & 18 & $\mathrm{H}$ \\
\hline 077 & $2+3$ & $8.65 \mathrm{E}-01$ & $7.39 \mathrm{E}-01$ & $7.54 \mathrm{E}-01$ & $7.46 \mathrm{E}-01$ & $5.62 \mathrm{E}-01$ & $9.92 \mathrm{E}-01$ & $6.99 \mathrm{E}-01$ & $6.91 \mathrm{E}-01$ & $6.95 \mathrm{E}-01$ & 10 & L \\
\hline 078 & 1 & 7.60E-01 & $5.90 \mathrm{E}-01$ & 5.77E-01 & 5.83E-01 & 4.39E-01 & 7.75E-01 & 5.86E-01 & 5.96E-01 & 5.91E-01 & 15 & $M$ \\
\hline 078 & 2 & $2.48 \mathrm{E}-01$ & 3.17E-01 & $3.65 \mathrm{E}-01$ & $3.41 \mathrm{E}-01$ & $2.57 \mathrm{E}-01$ & $4.53 \mathrm{E}-01$ & 2.97E-01 & $3.02 \mathrm{E}-01$ & $3.00 \mathrm{E}-01$ & 3 & VL \\
\hline 079 & 1 & $6.11 \mathrm{E}-01$ & $4.28 \mathrm{E}-01$ & 4.34E-01 & $4.31 \mathrm{E}-01$ & $3.24 \mathrm{E}-01$ & $5.72 \mathrm{E}-01$ & 4.67E-01 & 4.66E-01 & $4.66 \mathrm{E}-01$ & 11 & L \\
\hline 080 & 1 & $1.31 \mathrm{E}-01$ & $1.23 \mathrm{E}-01$ & $1.22 \mathrm{E}-01$ & $1.22 \mathrm{E}-01$ & $9.22 \mathrm{E}-02$ & $1.63 \mathrm{E}-01$ & $1.22 \mathrm{E}-01$ & $1.23 \mathrm{E}-01$ & $1.22 \mathrm{E}-01$ & 19 & $\mathrm{H}$ \\
\hline 080 & $2+3$ & $1.64 \mathrm{E}+00$ & $1.35 \mathrm{E}+00$ & $1.31 \mathrm{E}+00$ & $1.33 E+00$ & $1.00 \mathrm{E}+00$ & $1.77 \mathrm{E}+00$ & $1.29 \mathrm{E}+00$ & $1.29 E+00$ & $1.29 \mathrm{E}+00$ & 13 & $M$ \\
\hline 081 & 1 & $2.43 \mathrm{E}-01$ & $1.58 \mathrm{E}-01$ & $1.62 \mathrm{E}-01$ & $1.60 \mathrm{E}-01$ & $1.20 \mathrm{E}-01$ & $2.13 \mathrm{E}-01$ & 1.47E-01 & $1.48 \mathrm{E}-01$ & $1.47 \mathrm{E}-01$ & 10 & L \\
\hline 081 & 2 & 4.97E-01 & $3.70 \mathrm{E}-01$ & $3.30 \mathrm{E}-01$ & $3.50 \mathrm{E}-01$ & $2.63 \mathrm{E}-01$ & 4.67E-01 & 3.54E-01 & 3.70E-01 & $3.62 \mathrm{E}-01$ & 3 & VL \\
\hline 082 & 1 & 8.78E-02 & 4.07E-02 & $4.04 \mathrm{E}-02$ & 4.06E-02 & $3.04 \mathrm{E}-02$ & $5.41 \mathrm{E}-02$ & $4.25 \mathrm{E}-02$ & 4.30E-02 & $4.28 \mathrm{E}-02$ & 14 & $M$ \\
\hline 082 & 2 & $1.05 \mathrm{E}-01$ & $1.13 \mathrm{E}-01$ & $1.08 \mathrm{E}-01$ & $1.11 \mathrm{E}-01$ & $8.29 \mathrm{E}-02$ & $1.47 \mathrm{E}-01$ & $9.69 \mathrm{E}-02$ & $9.62 \mathrm{E}-02$ & $9.66 \mathrm{E}-02$ & 6 & $\mathrm{VL}$ \\
\hline 082 & 3 & $1.35 \mathrm{E}+00$ & $1.05 \mathrm{E}+00$ & $9.65 \mathrm{E}-01$ & $1.01 \mathrm{E}+00$ & 7.58E-01 & $1.35 \mathrm{E}+00$ & $9.19 \mathrm{E}-01$ & $9.12 \mathrm{E}-01$ & $9.15 \mathrm{E}-01$ & 5 & $\mathrm{VL}$ \\
\hline 083 & 1 & $1.50 \mathrm{E}-01$ & $1.43 \mathrm{E}-01$ & $1.42 \mathrm{E}-01$ & $1.42 \mathrm{E}-01$ & $1.07 \mathrm{E}-01$ & $1.89 \mathrm{E}-01$ & $1.42 \mathrm{E}-01$ & $1.40 \mathrm{E}-01$ & $1.41 \mathrm{E}-01$ & 18 & $\mathrm{H}$ \\
\hline 083 & 2 & $1.53 E+00$ & $1.13 E+00$ & $1.26 \mathrm{E}+00$ & $1.20 \mathrm{E}+00$ & $9.02 \mathrm{E}-01$ & $1.59 E+00$ & $1.17 \mathrm{E}+00$ & $1.16 \mathrm{E}+00$ & $1.16 \mathrm{E}+00$ & 8 & $\mathrm{~L}$ \\
\hline 084 & 1 & 7.57E-02 & $3.09 \mathrm{E}-02$ & $2.63 \mathrm{E}-02$ & $2.86 \mathrm{E}-02$ & $2.15 \mathrm{E}-02$ & $3.80 \mathrm{E}-02$ & $2.54 \mathrm{E}-02$ & $2.58 \mathrm{E}-02$ & $2.56 \mathrm{E}-02$ & 4 & $\mathrm{VL}$ \\
\hline 084 & 2 & 1.10E-01 & $1.51 \mathrm{E}-01$ & $1.72 \mathrm{E}-01$ & 1.61E-01 & $1.22 \mathrm{E}-01$ & $2.14 \mathrm{E}-01$ & $1.62 \mathrm{E}-01$ & 1.60E-01 & 1.61E-01 & 7 & $\mathrm{VL}$ \\
\hline 085 & 1 & $2.88 \mathrm{E}-01$ & $1.92 \mathrm{E}-01$ & $2.09 \mathrm{E}-01$ & 2.00E-01 & $1.51 \mathrm{E}-01$ & $2.66 \mathrm{E}-01$ & $1.92 \mathrm{E}-01$ & 1.96E-01 & $1.94 \mathrm{E}-01$ & 9 & L \\
\hline 085 & 2 & $2.88 \mathrm{E}-01$ & 4.37E-01 & $4.32 \mathrm{E}-01$ & 4.34E-01 & $3.27 \mathrm{E}-01$ & $5.77 \mathrm{E}-01$ & $3.43 \mathrm{E}-01$ & $3.56 \mathrm{E}-01$ & $3.50 \mathrm{E}-01$ & 7 & $\mathrm{VL}$ \\
\hline 086 & 1 & 1.13E-01 & $5.40 \mathrm{E}-02$ & 4.99E-02 & $5.20 \mathrm{E}-02$ & $3.74 \mathrm{E}-02$ & $7.21 \mathrm{E}-02$ & $6.31 \mathrm{E}-02$ & $6.08 \mathrm{E}-02$ & $6.20 \mathrm{E}-02$ & 2 & VL \\
\hline 087 & 1 & $3.13 \mathrm{E}-01$ & $1.94 \mathrm{E}-01$ & $1.95 \mathrm{E}-01$ & $1.94 \mathrm{E}-01$ & $1.46 \mathrm{E}-01$ & $2.59 \mathrm{E}-01$ & $1.94 \mathrm{E}-01$ & $1.95 \mathrm{E}-01$ & $1.95 \mathrm{E}-01$ & 20 & $\mathrm{VH}$ \\
\hline 088 & 1 & $1.23 \mathrm{E}-01$ & 7.37E-02 & $7.34 \mathrm{E}-02$ & $7.36 \mathrm{E}-02$ & $5.52 \mathrm{E}-02$ & $9.80 \mathrm{E}-02$ & 7.37E-02 & $7.36 \mathrm{E}-02$ & 7.37E-02 & 20 & $\mathrm{VH}$ \\
\hline 088 & 2 & $8.00 \mathrm{E}-04$ & $4.66 \mathrm{E}-02$ & $5.13 \mathrm{E}-02$ & $4.90 \mathrm{E}-02$ & $3.67 \mathrm{E}-02$ & $6.53 \mathrm{E}-02$ & $4.92 \mathrm{E}-02$ & $4.74 \mathrm{E}-02$ & $4.83 \mathrm{E}-02$ & 5 & $\mathrm{VL}$ \\
\hline 089 & 1 & $9.00 \mathrm{E}-02$ & $5.70 \mathrm{E}-02$ & $5.69 \mathrm{E}-02$ & $5.70 \mathrm{E}-02$ & $4.10 \mathrm{E}-02$ & $7.90 \mathrm{E}-02$ & $5.66 \mathrm{E}-02$ & $5.62 \mathrm{E}-02$ & $5.64 \mathrm{E}-02$ & 20 & $\mathrm{VH}$ \\
\hline 089 & 2 & $2.16 \mathrm{E}-01$ & $1.51 \mathrm{E}-01$ & $1.50 \mathrm{E}-01$ & $1.50 \mathrm{E}-01$ & $1.08 \mathrm{E}-01$ & $2.09 \mathrm{E}-01$ & $1.41 \mathrm{E}-01$ & 1.37E-01 & 1.39E-01 & 10 & L \\
\hline 090 & 1 & $1.39 \mathrm{E}-01$ & $8.11 \mathrm{E}-02$ & $8.18 \mathrm{E}-02$ & $8.15 \mathrm{E}-02$ & $5.87 \mathrm{E}-02$ & $1.13 \mathrm{E}-01$ & $8.22 \mathrm{E}-02$ & 8.17E-02 & $8.19 \mathrm{E}-02$ & 20 & $\mathrm{VH}$ \\
\hline 090 & 2 & 2.33E-01 & $1.93 \mathrm{E}-01$ & $1.89 \mathrm{E}-01$ & 1.91E-01 & $1.38 \mathrm{E}-01$ & $2.65 \mathrm{E}-01$ & 1.79E-01 & 1.77E-01 & $1.78 \mathrm{E}-01$ & 12 & $M$ \\
\hline 091 & 1 & $6.14 \mathrm{E}-01$ & 3.93E-01 & 4.10E-01 & $4.02 \mathrm{E}-01$ & $2.89 \mathrm{E}-01$ & 5.57E-01 & 4.07E-01 & 4.13E-01 & 4.10E-01 & 13 & $M$ \\
\hline 092 & 1 & $1.22 \mathrm{E}-01$ & $8.66 \mathrm{E}-02$ & $8.80 \mathrm{E}-02$ & $8.73 \mathrm{E}-02$ & $6.55 \mathrm{E}-02$ & $1.16 \mathrm{E}-01$ & $8.59 \mathrm{E}-02$ & 8.64E-02 & $8.62 \mathrm{E}-02$ & 18 & H \\
\hline 093 & 1 & $1.20 \mathrm{E}-01$ & $1.48 \mathrm{E}-01$ & $1.46 \mathrm{E}-01$ & 1.47E-01 & $1.10 \mathrm{E}-01$ & $1.96 \mathrm{E}-01$ & $1.49 \mathrm{E}-01$ & $1.46 \mathrm{E}-01$ & $1.48 \mathrm{E}-01$ & 17 & $\mathrm{H}$ \\
\hline 093 & 2 & $1.36 \mathrm{E}+00$ & $1.09 \mathrm{E}+00$ & $1.05 E+00$ & $1.07 \mathrm{E}+00$ & $8.04 \mathrm{E}-01$ & $1.43 E+00$ & $9.42 \mathrm{E}-01$ & $9.39 \mathrm{E}-01$ & $9.41 \mathrm{E}-01$ & 7 & $\mathrm{VL}$ \\
\hline 094 & 1 & $2.12 \mathrm{E}-01$ & $1.86 \mathrm{E}-01$ & $1.80 \mathrm{E}-01$ & $1.83 \mathrm{E}-01$ & 1.37E-01 & $2.44 \mathrm{E}-01$ & $1.82 \mathrm{E}-01$ & $1.80 \mathrm{E}-01$ & $1.81 \mathrm{E}-01$ & 16 & $\mathrm{M}$ \\
\hline 095 & 1 & 7.07E-02 & $8.28 \mathrm{E}-02$ & $8.90 \mathrm{E}-02$ & $8.59 \mathrm{E}-02$ & $6.47 \mathrm{E}-02$ & $1.14 \mathrm{E}-01$ & $7.85 \mathrm{E}-02$ & $7.84 \mathrm{E}-02$ & $7.85 \mathrm{E}-02$ & 6 & $\mathrm{VL}$ \\
\hline 095 & 2 & $8.96 \mathrm{E}-01$ & $5.61 \mathrm{E}-01$ & 4.97E-01 & $5.29 \mathrm{E}-01$ & $3.98 \mathrm{E}-01$ & $7.03 \mathrm{E}-01$ & $5.35 \mathrm{E}-01$ & $5.41 \mathrm{E}-01$ & $5.38 \mathrm{E}-01$ & 7 & $\mathrm{VL}$ \\
\hline 096 & $1+2$ & $5.35 \mathrm{E}-02$ & $7.42 \mathrm{E}-02$ & $7.29 \mathrm{E}-02$ & $7.36 \mathrm{E}-02$ & $5.52 \mathrm{E}-02$ & $9.80 \mathrm{E}-02$ & 7.41E-02 & $7.24 \mathrm{E}-02$ & 7.33E-02 & 16 & $M$ \\
\hline 097 & 1 & $1.89 \mathrm{E}-01$ & $9.62 \mathrm{E}-02$ & $9.36 \mathrm{E}-02$ & $9.49 \mathrm{E}-02$ & 7.12E-02 & $1.27 \mathrm{E}-01$ & $9.24 \mathrm{E}-02$ & 9.07E-02 & $9.16 \mathrm{E}-02$ & 14 & $\mathrm{M}$ \\
\hline 097 & 2 & $6.67 \mathrm{E}-01$ & $5.08 \mathrm{E}-01$ & $5.38 \mathrm{E}-01$ & $5.23 \mathrm{E}-01$ & $3.92 \mathrm{E}-01$ & $6.97 \mathrm{E}-01$ & 5.30E-01 & $5.24 \mathrm{E}-01$ & $5.27 \mathrm{E}-01$ & 11 & $\mathrm{~L}$ \\
\hline 098 & $1+2$ & $1.54 \mathrm{E}-01$ & $5.57 \mathrm{E}-02$ & $5.36 \mathrm{E}-02$ & 5.47E-02 & $4.01 \mathrm{E}-02$ & $7.44 \mathrm{E}-02$ & $5.32 \mathrm{E}-02$ & $5.42 \mathrm{E}-02$ & 5.37E-02 & 14 & M \\
\hline
\end{tabular}




\begin{tabular}{|c|c|c|c|c|c|c|c|c|c|c|c|}
\hline 098 & $3+4$ & 5.01E-01 & $2.90 \mathrm{E}-01$ & $4.26 \mathrm{E}-01$ & $3.58 \mathrm{E}-01$ & $2.63 \mathrm{E}-01$ & $4.88 \mathrm{E}-01$ & $3.48 \mathrm{E}-01$ & $3.38 \mathrm{E}-01$ & $3.43 \mathrm{E}-01$ & 3 \\
\hline 99 & 1 & $1.27 \mathrm{E}-01$ & 7.79E-02 & $8.42 \mathrm{E}-02$ & 8.11E-02 & $5.95 \mathrm{E}-02$ & $1.10 \mathrm{E}-01$ & 8.02E-02 & 8.10E-02 & 8.06E-02 & 11 \\
\hline 099 & $2+3+4$ & 6.73E-01 & $5.32 \mathrm{E}-01$ & $6.45 \mathrm{E}-01$ & $5.88 \mathrm{E}-01$ & 4.32E-01 & 8.01E-01 & $5.36 \mathrm{E}-01$ & $5.41 \mathrm{E}-01$ & 5.39E-01 & 6 \\
\hline
\end{tabular}

Table S3: A table of $v_{\min }, v_{\max }, \varepsilon_{\max }$, and $v$ at $\varepsilon_{\max }$ for each of the 164 transitions. Those were obtained from the higher resolution digitization used for the $f_{\text {exp,g1 }}$ and $f_{\text {exp,n1 }}$ data.

\begin{tabular}{|c|c|c|c|c|c|}
\hline ID & Band & $V_{\min }$ & $v_{\max }$ & $\varepsilon_{\max }$ & $v$ at $\varepsilon_{\max }$ \\
\hline 000 & 1 & 42359 & 54873 & 10971 & 51860 \\
\hline 001 & 1 & 41718 & 54825 & 10550 & 50128 \\
\hline 002 & 1 & 39330 & 54832 & 10405 & 49851 \\
\hline 003 & 1 & 37383 & 54918 & 11377 & 48914 \\
\hline 004 & 1 & 39137 & 54853 & 25922 & 44827 \\
\hline 005 & 1 & 36268 & 54846 & 24476 & 41154 \\
\hline 006 & 1 & 36804 & 49535 & 5826 & 43960 \\
\hline 007 & 1 & 37306 & 51108 & 18941 & 41819 \\
\hline 008 & 1 & 40187 & 49711 & 13819 & 45323 \\
\hline 009 & 1 & 39914 & 49308 & 14927 & 44941 \\
\hline 010 & 1 & 23813 & 37857 & 3150 & 33568 \\
\hline 011 & 2 & 37088 & 47612 & 20883 & 41743 \\
\hline 012 & 1 & 20066 & 34864 & 1170 & 27443 \\
\hline 012 & 2 & 34864 & 40627 & 10948 & 39539 \\
\hline 013 & 1 & 22386 & 35775 & 1085 & 29223 \\
\hline 013 & 2 & 35923 & 45191 & 10520 & 40300 \\
\hline 014 & 1 & 24418 & 32775 & 10658 & 28702 \\
\hline 014 & 2 & 32775 & 39935 & 5394 & 35294 \\
\hline 015 & 1 & 34247 & 46141 & 11843 & 42548 \\
\hline 015 & 2 & 46141 & 54542 & 12078 & 51122 \\
\hline 016 & 1 & 34758 & 50043 & 3618 & 43277 \\
\hline 017 & 2 & 41550 & 52933 & 4414 & 49486 \\
\hline 018 & 2 & 31679 & 53032 & 1732 & 45441 \\
\hline 019 & 2 & 32244 & 49046 & 1569 & 44719 \\
\hline 020 & $1+2$ & 25037 & 41830 & 16776 & 38158 \\
\hline 021 & $1+2$ & 22004 & 40218 & 13906 & 34582 \\
\hline 022 & 1 & 20841 & 33406 & 17499 & 26659 \\
\hline 022 & 2 & 33406 & 44993 & 20295 & 39530 \\
\hline 023 & 2 & 25556 & 43304 & 1636 & 38001 \\
\hline 024 & 2 & 28525 & 43657 & 10553 & 37804 \\
\hline 025 & 2 & 24787 & 39897 & 11678 & 34329 \\
\hline 026 & 2 & 26365 & 39890 & 22427 & 31644 \\
\hline 026 & 3 & 39890 & 47019 & 14072 & 43743 \\
\hline 027 & 1 & 16519 & 26079 & 46730 & 19410 \\
\hline 027 & $2+3$ & 26079 & 40228 & 12226 & 31332 \\
\hline 028 & 1 & 14971 & 28398 & 25220 & 21288 \\
\hline 029 & 1 & 17858 & 23207 & 652 & 21617 \\
\hline 029 & 2 & 23207 & 39961 & 22689 & 28631 \\
\hline 030 & 1 & 22068 & 33618 & 12007 & 29921 \\
\hline 030 & 2 & 33618 & 40024 & 11615 & 38542 \\
\hline 031 & 2 & 27095 & 40759 & 14084 & 33879 \\
\hline 032 & 1 & 38085 & 50082 & 10943 & 44381 \\
\hline 033 & 1 & 28584 & 41455 & 47744 & 32154 \\
\hline 033 & 2 & 41591 & 47594 & 2779 & 46048 \\
\hline 034 & $1+2+3$ & 24175 & 42775 & 14306 & 32749 \\
\hline 035 & 1 & 36108 & 47335 & 12845 & 43701 \\
\hline
\end{tabular}




\begin{tabular}{|c|c|c|c|c|c|}
\hline 036 & 1 & 20047 & 35033 & 22313 & 25532 \\
\hline 036 & 2 & 35033 & 46613 & 10467 & 40178 \\
\hline 037 & 1 & 20175 & 34082 & 20584 & 27969 \\
\hline 038 & $1+2$ & 15176 & 30090 & 17957 & 23478 \\
\hline 039 & 1 & 20054 & 32378 & 26560 & 26838 \\
\hline 040 & 1 & 24620 & 31263 & 23796 & 28112 \\
\hline 040 & 2 & 31263 & 38731 & 26817 & 34224 \\
\hline 041 & $2+3$ & 43506 & 54936 & 56160 & 52292 \\
\hline 042 & 2 & 42969 & 48644 & 8384 & 47140 \\
\hline 042 & 3 & 48644 & 54857 & 53151 & 51385 \\
\hline 043 & 2 & 42913 & 48636 & 8458 & 47107 \\
\hline 043 & 3 & 48636 & 54853 & 57646 & 51491 \\
\hline 044 & 1 & 33529 & 41294 & 3121 & 34955 \\
\hline 044 & $2+3$ & 41294 & 54279 & 44732 & 49176 \\
\hline 045 & 1 & 33825 & 40954 & 1977 & 34991 \\
\hline 045 & $2+3$ & 41103 & 54319 & 42242 & 48602 \\
\hline 046 & 1 & 34662 & 41404 & 1481 & 37065 \\
\hline 046 & 2 & 42179 & 49019 & 41503 & 52040 \\
\hline 047 & 1 & 31659 & 38533 & 2566 & 34780 \\
\hline 047 & 2 & 38533 & 46382 & 9968 & 42570 \\
\hline 048 & 1 & 31058 & 35779 & 2276 & 33076 \\
\hline 048 & 2 & 35779 & 44684 & 16149 & 38519 \\
\hline 048 & 3 & 44684 & 53005 & 20297 & 49535 \\
\hline 049 & $1+2$ & 25184 & 44992 & 9055 & 39723 \\
\hline 050 & 2 & 42474 & 48436 & 7810 & 46989 \\
\hline 050 & 3 & 48436 & 54845 & 48055 & 51911 \\
\hline 051 & 2 & 41842 & 48512 & 9536 & 45389 \\
\hline 051 & 3 & 48512 & 54912 & 50474 & 51953 \\
\hline 052 & 1 & 35218 & 40651 & 1006 & 36790 \\
\hline 052 & 2 & 40651 & 48930 & 7453 & 47294 \\
\hline 052 & 3 & 48930 & 54816 & 41871 & 52092 \\
\hline 053 & 1 & 22342 & 31531 & 3048 & 28442 \\
\hline 053 & 2 & 31531 & 40942 & 6260 & 35899 \\
\hline 054 & 1 & 24482 & 31963 & 1907 & 30344 \\
\hline 054 & 2 & 31963 & 40190 & 5848 & 36746 \\
\hline 054 & 3 & 40190 & 45135 & 7604 & 43902 \\
\hline 054 & 4 & 45135 & 51427 & 12252 & 47909 \\
\hline 055 & 1 & 22944 & 39389 & 9214 & 31565 \\
\hline 055 & 2 & 39389 & 47313 & 6428 & 44080 \\
\hline 056 & 1 & 20947 & 33946 & 17404 & 24838 \\
\hline 057 & 1 & 25763 & 36336 & 3374 & 30511 \\
\hline 057 & 2 & 36471 & 43385 & 9168 & 39646 \\
\hline 058 & 1 & 26754 & 37029 & 3490 & 32656 \\
\hline 058 & 2 & 37029 & 43792 & 7883 & 40419 \\
\hline 059 & 1 & 26179 & 36157 & 3564 & 30525 \\
\hline 059 & 2 & 36157 & 43259 & 10597 & 39225 \\
\hline 060 & 1 & 27505 & 35826 & 4583 & 31010 \\
\hline 060 & 2 & 35826 & 43566 & 10104 & 39340 \\
\hline 061 & 1 & 23041 & 35574 & 4927 & 27083 \\
\hline 061 & 2 & 35574 & 40169 & 5914 & 38522 \\
\hline 061 & 3 & 40169 & 46591 & 20988 & 43065 \\
\hline 062 & 1 & 27338 & 41909 & 16172 & 35102 \\
\hline 062 & 2 & 41909 & 47773 & 12574 & 44972 \\
\hline 063 & 1 & 27443 & 38574 & 33667 & 30686 \\
\hline 063 & 2 & 38574 & 46351 & 9054 & 42843 \\
\hline
\end{tabular}




\begin{tabular}{|c|c|c|c|c|c|}
\hline 064 & 1 & 32243 & 36817 & 1926 & 34811 \\
\hline 064 & $2+3$ & 36817 & 45310 & 24078 & 40084 \\
\hline 065 & 1 & 32465 & 37811 & 1293 & 35651 \\
\hline 065 & $2+3$ & 37811 & 54193 & 33155 & 51033 \\
\hline 066 & 1 & 20402 & 35579 & 15065 & 26060 \\
\hline 066 & 2 & 35579 & 46566 & 6689 & 43544 \\
\hline 067 & 1 & 32050 & 38140 & 2865 & 34568 \\
\hline 067 & 2 & 38140 & 44393 & 7879 & 41915 \\
\hline 067 & 3 & 44393 & 50346 & 33980 & 49062 \\
\hline 068 & 1 & 20419 & 31158 & 4293 & 24104 \\
\hline 068 & 2 & 31158 & 37549 & 4285 & 35638 \\
\hline 068 & 3 & 37549 & 48601 & 16045 & 43525 \\
\hline 069 & 1 & 26025 & 42437 & 24024 & 35225 \\
\hline 070 & 1 & 25959 & 42286 & 23482 & 34729 \\
\hline 070 & 2 & 42286 & 47253 & 11654 & 45327 \\
\hline 071 & 2 & 31948 & 44213 & 17292 & 39652 \\
\hline 072 & 2 & 33079 & 43851 & 18643 & 39493 \\
\hline 073 & 1 & 25704 & 36567 & 16381 & 29586 \\
\hline 073 & 2 & 36567 & 44715 & 12977 & 41082 \\
\hline 074 & 1 & 24930 & 37241 & 27024 & 30128 \\
\hline 074 & 2 & 37241 & 45245 & 18013 & 41161 \\
\hline 075 & $2+3$ & 31884 & 42619 & 17938 & 37302 \\
\hline 076 & 1 & 30422 & 40151 & 23786 & 34998 \\
\hline 077 & 1 & 20110 & 30898 & 6578 & 23548 \\
\hline 077 & $2+3$ & 30898 & 46713 & 14234 & 38664 \\
\hline 078 & 1 & 20998 & 35914 & 23553 & 26695 \\
\hline 078 & 2 & 35914 & 46099 & 9778 & 43870 \\
\hline 079 & 1 & 25043 & 37217 & 17069 & 31651 \\
\hline 080 & 1 & 29950 & 39999 & 5045 & 33871 \\
\hline 080 & $2+3$ & 39999 & 52130 & 41771 & 47578 \\
\hline 081 & 1 & 25979 & 36967 & 7434 & 29944 \\
\hline 081 & 2 & 36967 & 43458 & 25409 & 40534 \\
\hline 082 & 1 & 25637 & 32383 & 2846 & 28911 \\
\hline 082 & 2 & 32639 & 38287 & 6056 & 35538 \\
\hline 082 & 3 & 38287 & 46784 & 51149 & 41911 \\
\hline 083 & 1 & 30454 & 40053 & 6825 & 35221 \\
\hline 083 & 2 & 40053 & 49743 & 66586 & 44665 \\
\hline 084 & 1 & 27022 & 31697 & 1928 & 29149 \\
\hline 084 & 2 & 31697 & 38148 & 9826 & 35617 \\
\hline 085 & 1 & 23735 & 37136 & 6508 & 30392 \\
\hline 085 & 2 & 37260 & 44540 & 19058 & 42992 \\
\hline 086 & 1 & 38057 & 45592 & 3492 & 42798 \\
\hline 087 & 1 & 29024 & 38436 & 11992 & 31977 \\
\hline 088 & 1 & 36467 & 45278 & 5371 & 39158 \\
\hline 088 & 2 & 45430 & 51885 & 2900 & 49706 \\
\hline 089 & 1 & 34250 & 42202 & 3734 & 36557 \\
\hline 089 & 2 & 42202 & 50736 & 7197 & 46438 \\
\hline 090 & 1 & 33459 & 40920 & 5581 & 36007 \\
\hline 090 & 2 & 41077 & 49249 & 9389 & 44938 \\
\hline 091 & 1 & 28984 & 42623 & 10984 & 37343 \\
\hline 092 & 1 & 27387 & 34766 & 5355 & 30306 \\
\hline 093 & 1 & 29594 & 39331 & 7099 & 33067 \\
\hline 093 & 2 & 39331 & 49827 & 53283 & 43955 \\
\hline 094 & 1 & 28481 & 38073 & 9784 & 31789 \\
\hline 095 & 1 & 26931 & 37042 & 2891 & 31131 \\
\hline
\end{tabular}




$\begin{array}{lccccc}095 & 2 & 37042 & 44972 & 43790 & 41254 \\ 096 & 1+2 & 22004 & 36758 & 2207 & 26980 \\ 097 & 1 & 21954 & 34738 & 3162 & 27480 \\ 097 & 2 & 34738 & 44208 & 30740 & 39331 \\ 098 & 1+2 & 21138 & 34498 & 1607 & 29540 \\ 098 & 3+4 & 34498 & 48466 & 15362 & 45672 \\ 099 & 1 & 21847 & 31282 & 4220 & 25534 \\ 099 & 2+3+4 & 35018 & 47319 & 18945 & 44250\end{array}$

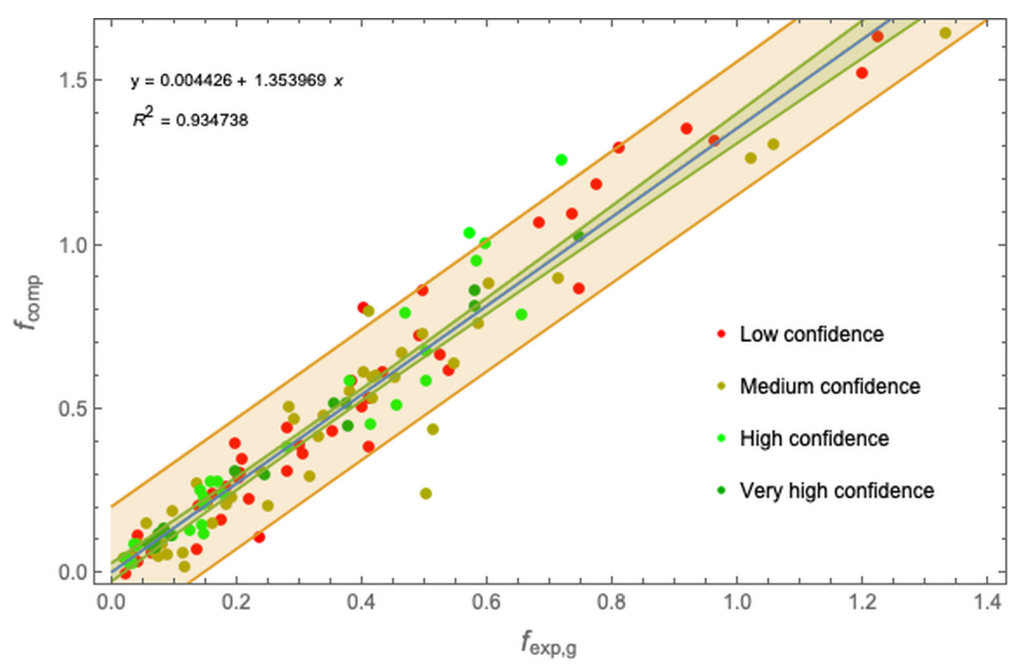

Figure S1. The plot of $f_{\text {comp }}$ vs. $f_{\text {exp, },}$ after excluding 37 "very low confidence" points from plot Fig. 3 left in the main manuscript. The points are colored by confidence level, as indicated in the legend. The blue line is a linear regression. The orange lines and area indicate $95 \%$ confidence bands for the data, while the green lines and area indicate the $95 \%$ mean confidence prediction bands.

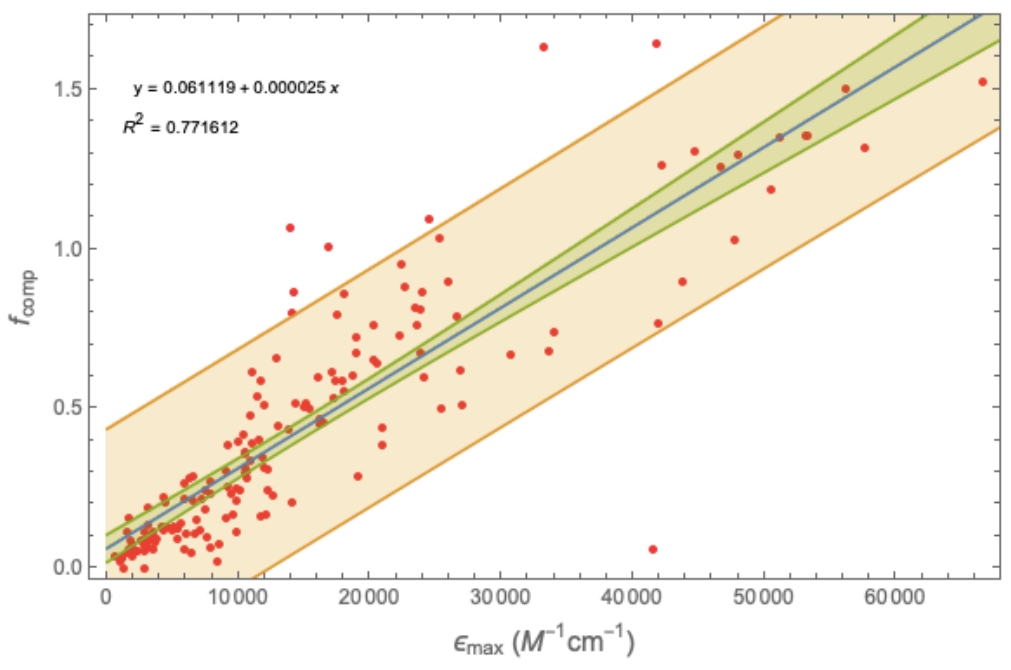

Figure S2. The plot of $f_{\text {comp }}$ vs. $\varepsilon_{\max }$ for all 164 transitions. The blue line is a linear regression. The orange lines and area indicate $95 \%$ confidence bands for the data, while the green lines and area indicate the $95 \%$ mean confidence prediction bands. 


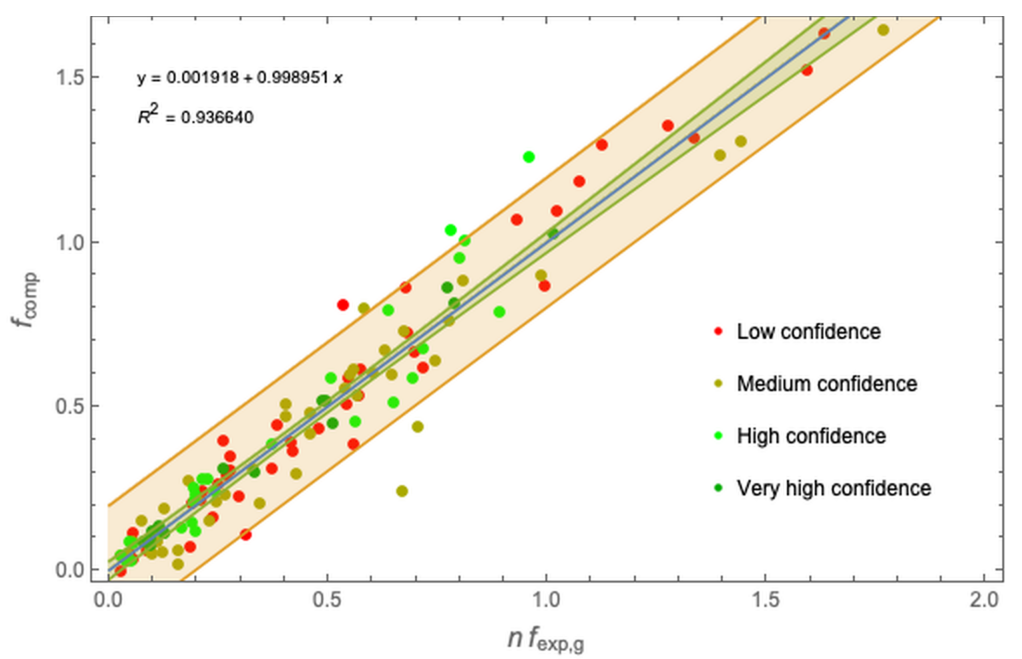

Figure S3. The plot of $f_{\text {comp }}$ vs. $n \times f_{\text {exp }, g}$ for the 164 transitions, where $n$ is the solvent refractive index, after excluding 37 "very low confidence" points from plot Fig. 4 left in the main manuscript. The points are colored by confidence level, as indicated in the legend. The blue line is a linear regression. The orange lines and area indicate $95 \%$ confidence bands for the data, while the green lines and area indicate the 95\% mean confidence prediction bands.
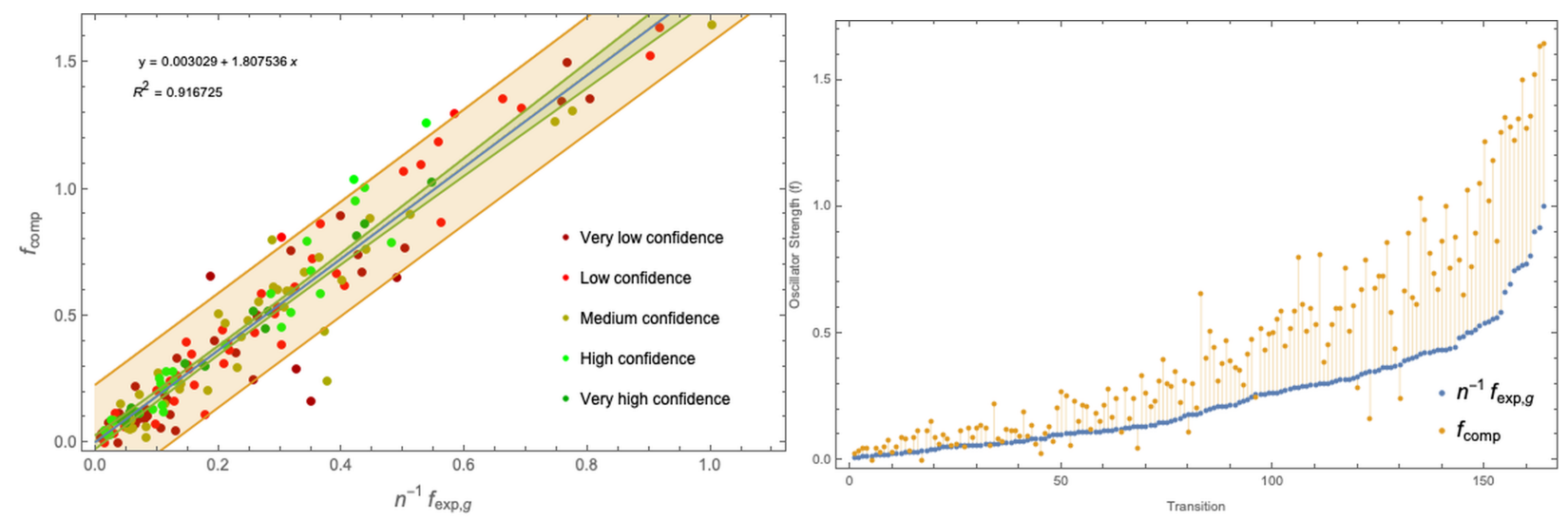

Figure S4. Left: $f_{\text {comp }}$ vs. $n^{-1} \times f_{\text {exp,g }}$ for the 164 transitions, where $n$ is the solvent refractive index. The points are colored by confidence level, as indicated in the legend. The blue line is a linear regression. The orange lines and area indicate $95 \%$ confidence bands for the data, while the green lines and area indicate the $95 \%$ mean confidence prediction bands. Right: $f_{\text {comp }}$ and $n^{-1} \times f_{\text {exp,g }}$ for each transition ordered by increasing strength of $n^{-1} \times f_{\text {exp, },}$. The lines connecting the points are the absolute differences. 


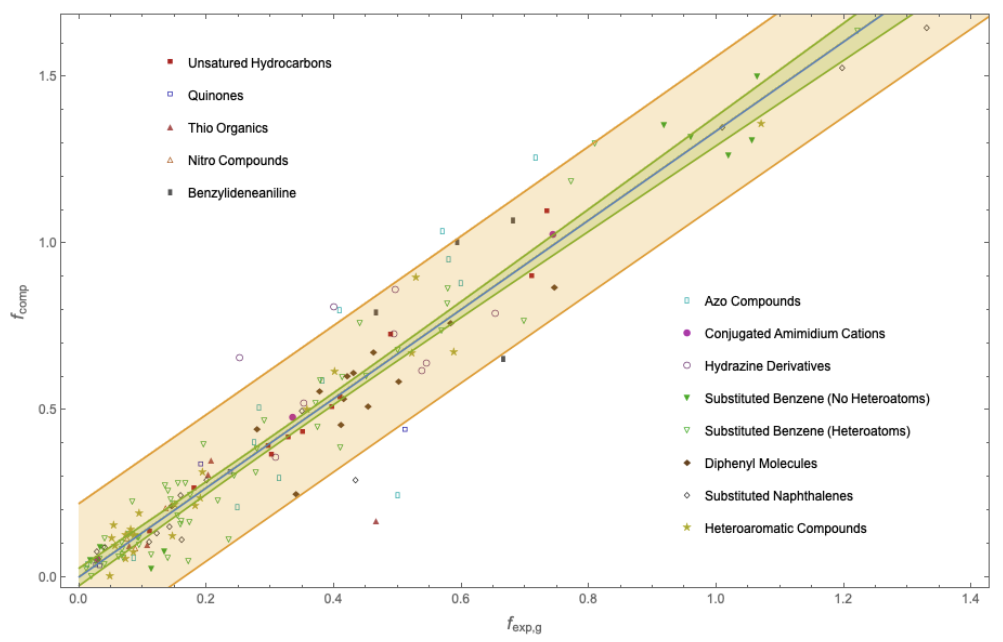

Figure S5. The plot of $f_{\text {comp }}$ vs. $f_{\text {exp,g }}$ where the data points are colored according to the type of molecule. The blue line is a linear regression. The orange lines and area indicate $95 \%$ confidence bands for the data, while the green lines and area indicate the $95 \%$ mean confidence prediction bands.

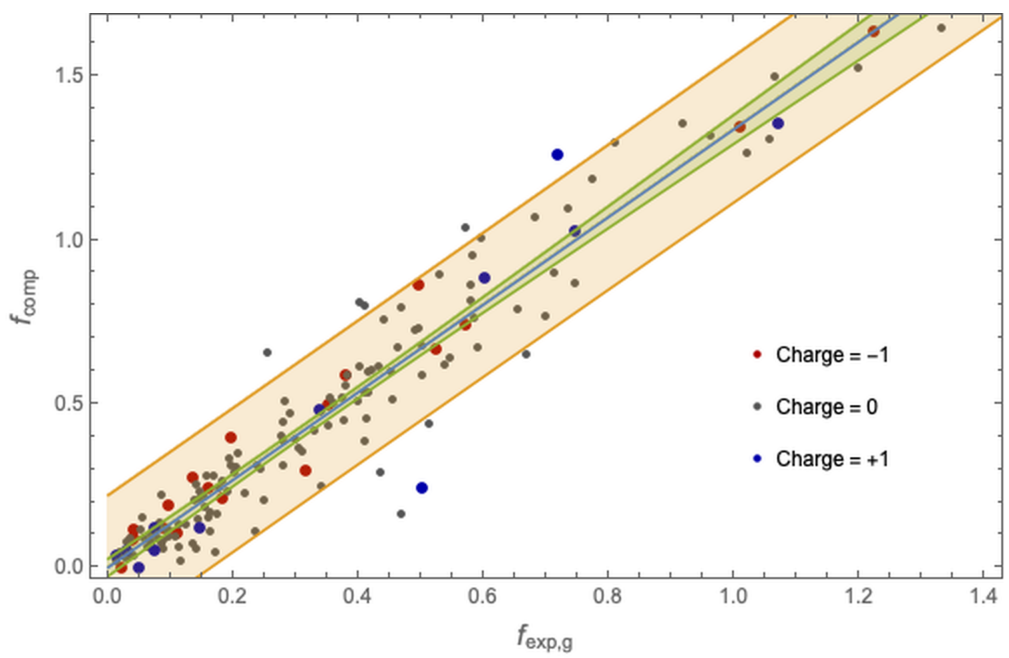

Figure S6. The plot of $f_{\text {comp }}$ vs. $f_{\text {exp,g }}$ where the data points are colored according to the molecular charge. The blue line is a linear regression. The orange lines and area indicate $95 \%$ confidence bands for the data, while the green lines and area indicate the $95 \%$ mean confidence prediction bands.

\section{REFERENCES}

1. UV Atlas of Organic Compounds. In UV Atlas of Organic Compounds / UV Atlas organischer Verbindungen, Springer US: Boston, MA, 1967; pp 5-605.

2. Winget, P.; Dolney, D. M.; Giesen, D. J.; Cramer, C. J.; Truhlar, D. G., Minnesota solvent descriptor database. Minneapolis, MN: Department of Chemistry and Supercomputer Institute 1999. 